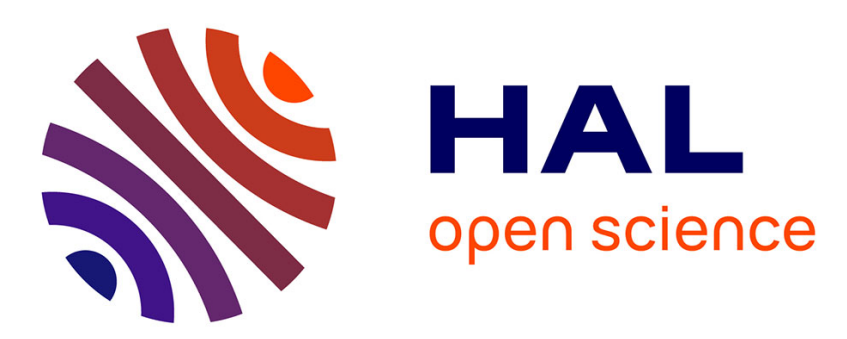

\title{
Molecular copper iodide clusters: a distinguishing family of mechanochromic luminescent compounds
}

\author{
Sandrine Perruchas
}

\section{To cite this version:}

Sandrine Perruchas. Molecular copper iodide clusters: a distinguishing family of mechanochromic luminescent compounds. Dalton Transactions, 2021, 50 (35), pp.12031-12044. 10.1039/d1dt01827b . hal-03355984

\author{
HAL Id: hal-03355984 \\ https://hal.science/hal-03355984
}

Submitted on 8 Oct 2021

HAL is a multi-disciplinary open access archive for the deposit and dissemination of scientific research documents, whether they are published or not. The documents may come from teaching and research institutions in France or abroad, or from public or private research centers.
L'archive ouverte pluridisciplinaire HAL, est destinée au dépôt et à la diffusion de documents scientifiques de niveau recherche, publiés ou non, émanant des établissements d'enseignement et de recherche français ou étrangers, des laboratoires publics ou privés. 


\title{
Molecular copper iodide clusters: a distinguishing family of mechanochromic luminescent
} compounds

\author{
Sandrine Perruchas* \\ Université de Nantes, CNRS, Institut des Matériaux Jean Rouxel, IMN, F-44000 Nantes, France. \\ Phone: (+33)(0)2 403763 35. E-mail: sandrine.perruchas@cnrs-imn.fr
}

\begin{abstract}
.
Mechanochromic luminescent materials displaying switchable luminescence properties in response to external mechanical force are currently attracting wide interest because of their multiple potential applications. In the growing number of mechanochromic luminescent compounds, the mechanochromic complexes based on copper present appealing features with a large variety of mechanochromic properties and economical advantages over other metals. Among Cu-based compounds, the molecular copper iodide clusters of cubane geometry formulated $\left[\mathrm{Cu}_{4} \mathrm{I}_{4} \mathrm{~L}_{4}\right](\mathrm{L}=$ organic ligand), stand out. Indeed, they can exhibit multiple luminescent stimuli-responsive properties, being particularly suitable for the development of multifunctional photoactive systems. This perspective describes the survey of these mechanochromic luminescent cubane copper iodide clusters. Based on our investigations, their mechanochromic luminescent properties are presented along with the study of the underlying mechanism. Establishment of structure-properties relationships supported by various characterization techniques and associated to theoretical investigations permit to get insights into the mechanism at play. Studies of other researcher groups are also described and illustrate the interest shown by these mechanochromic compounds. Mechanically-responsive films are reported, demonstrating the potential use in a range of applications of such copper-based stimuli-responsive materials. Current challenges that faces the development of technological applications are finally outlined.
\end{abstract}

Keywords. luminescence mechanochromism, copper iodide clusters, cuprophilic interactions, mechanically responsive materials. 


\section{Introduction.}

Mechanochromic luminescent materials displaying switchable luminescence properties in response to external mechanical force are currently attracting wide interest for potential applications in strain detection, optical recording, storage and anti-counterfeiting, among others. ${ }^{1-7}$ Regarding their potential applications, one of the most attractive feature of these stimuli-responsive materials is the straightforward detection of the emission changes by simple non-invasive spectroscopic means or even with the naked eye. ${ }^{8-11}$ Even though the number of reported compounds exhibiting luminescence mechanochromism has greatly increased over the past decade, in-depth studies analysing the underlying mechanisms remain relatively rare. However, such studies are of crucial importance not only from a fundamental point of view but also to guide further development of these stimuliresponsive materials with optimized properties.

The majority of the mechanochromic luminescent compounds are based on organic molecules, ${ }^{12-14}$ in comparison with the metal-based compounds. ${ }^{15}$ The latter demonstrated nonetheless a rich variety of mechanochromic properties, mainly based on $\mathrm{Au}^{16-29}$ and $\mathrm{Pt}^{30-41}$ complexes. Examples of $\mathrm{Zn},{ }^{4-49}$ $\mathrm{Al}^{50,51} \operatorname{Ir}^{52-62}$ and $\mathrm{Ag}^{63-71}$-based compounds have been also described as well as organoboron complexes. ${ }^{72-82}$ Several $\mathrm{Cu}$ complexes ${ }^{83-105}$ have been reported too and in addition to their original mechanochromic properties, their economical interest compared with other metals, open appealing perspectives of applications. ${ }^{106}$ The first copper-based mechanochromic complex was indeed a molecular copper iodide cluster of cubane geometry, formulated $\left[\mathrm{Cu}_{4} \mathrm{I}_{4} \mathrm{~L}_{4}\right]$ ( $\mathrm{L}=$ phosphine ligand), reported by our group. ${ }^{107}$ The cubane molecular structure of these tetranuclear clusters can be described as a distorted cube built on four copper(I) atoms and four iodine atoms, the ligands (L) coordinating each copper atom which is then in a tetrahedral coordination environment (Figure 1). This structure can be also viewed as a $\mathrm{Cu}_{4}$ tetrahedron included within a larger $\mathrm{I}_{4}$ one and was first described for the $\left[\mathrm{Cu}_{4} \mathrm{Cl}_{4}\left(\mathrm{PPh}_{3}\right)_{4}\right]$ cluster in $1974 .{ }^{108}$ Followed by the report of this original mechanochromic luminescent copper iodide cluster, our group and others have demonstrated the rich luminescence mechanochromism of these polymetallic compounds. ${ }^{107,109-123}$ Indeed, among the mechanochromic luminescent compounds, they stand out because of their propensity to exhibit multiple stimuli-responsive properties, with possible luminescence thermochromism and/or solvatochromism for the best known, being particularly suitable for the development of multifunctional photoactive systems. ${ }^{124-129}$ Regarding applications, the potential of $\left[\mathrm{Cu}_{4} \mathrm{I}_{4} \mathrm{~L}_{4}\right]$ clusters as efficient phosphors have been already demonstrated for lighting devices. ${ }^{130-132}$
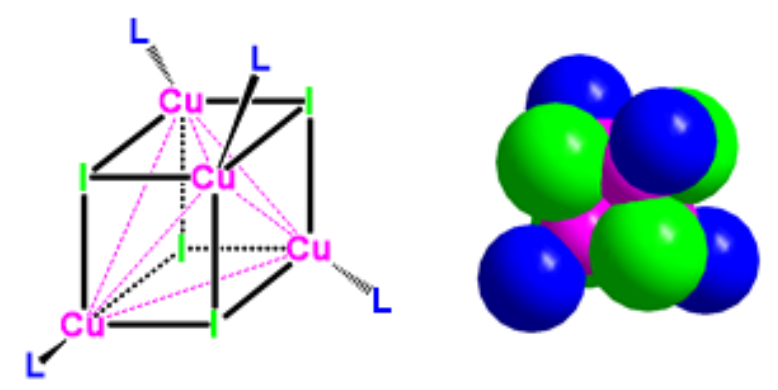

Figure 1. Different representations of the molecular structure of the cubane cluster formulated $\left[\mathrm{Cu}_{4} \mathrm{I}_{4} \mathrm{~L}_{4}\right](\mathrm{L}=$ ligand). The $\mathrm{Cu}-\mathrm{Cu}$ interactions are shown as dotted pink lines.

Here, we report the survey of this family of mechanochromic luminescent compounds consisting of the $\left[\mathrm{Cu}_{4} \mathrm{I}_{4} \mathrm{~L}_{4}\right]$ cubane copper iodide clusters. Based on our investigations, their mechanochromic luminescent properties are presented along with the study of the underlying mechanism that was conducted through the establishment of structure-properties relationships supported by various characterization techniques and associated to theoretical investigations. Studies of other researchers 
are also described and illustrate the interest shown by these mechanochromic compounds. Mechanically-responsive films are eventually described, demonstrating the potential use in a range of applications of such copper-based stimuli-responsive materials.

\section{Mechanochromic luminescent $\left[\mathrm{Cu}_{4} \mathbf{I}_{4} \mathbf{L}_{4}\right]$ clusters.}

Attractive photoluminescence properties. Even when structural investigations on the tetranuclear copper iodide $\left[\mathrm{Cu}_{4} \mathrm{I}_{4} \mathrm{~L}_{4}\right]$ clusters were still relatively limited, ${ }^{108,133-135}$ the temperature-dependent emission properties coined as fluorescence thermochromism, was already described for the cluster with the pyridine ligand. ${ }^{136}$ This first report demonstrated the appealing luminescence properties of such compounds which then rapidly attracted scientists attention. ${ }^{137,138}$ Numerous clusters with Nbased ligands were subsequently investigated and showed rich photophysical properties including the noteworthy contribution of the group of P. C. Ford. ${ }^{139}$ At the early stages of our investigations, photophysical studies of clusters with phosphines as ligands were scarce with two examples having $\mathrm{P}\left({ }^{\mathrm{n}} \mathrm{Bu}_{3}\right)_{4}$ and a phosphole derivative as ligands. ${ }^{140,141}$ In addition to their potentially rich photoluminescence properties, the phosphine-based clusters attracted our intention because of their enhanced chemical stability over the $\mathrm{N}$-based ligands ( $\mathrm{Cu}-\mathrm{P}$ bond being more stable than $\mathrm{Cu}-\mathrm{N}$ one). Chemical stability is indeed an essential criterion for the synthesis of materials based on these phosphors.
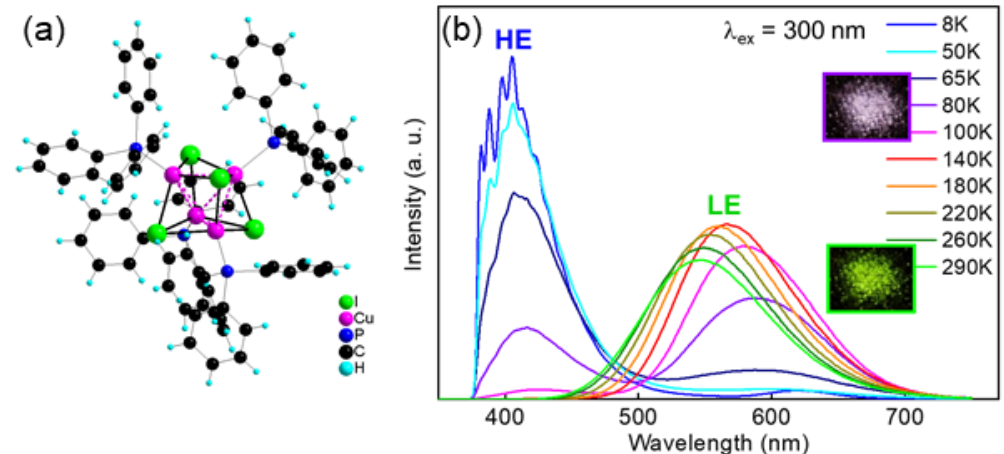

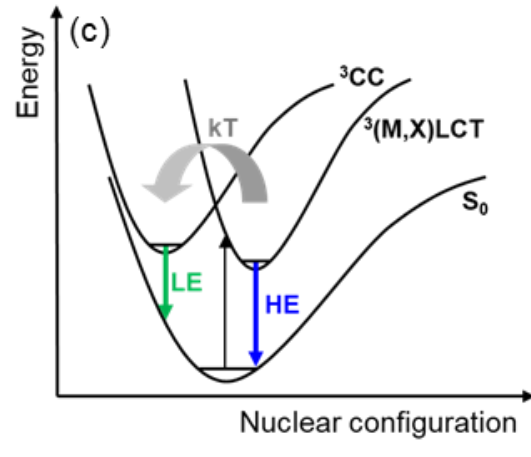

Figure 2. (a) Molecular structure of $\left[\mathrm{Cu}_{4} \mathrm{I}_{4}\left(\mathrm{PPh}_{3}\right)_{4}\right]$. (b) Temperature-dependent emission spectra with the two, $\mathrm{HE}$ and LE, emission bands. (c) Simplified energy diagram illustrating the luminescence thermochromism.

The synthesis of these clusters is commonly conducted in solution by reacting $\mathrm{CuI}$ with the corresponding ligands. The reaction product is often obtained as a white crystalline powder in relatively high synthesis yields. The luminescence thermochromism of the phosphine-based clusters was firstly evaluated by carrying out a comparative study of three $\left[\mathrm{Cu}_{4} \mathrm{I}_{4} \mathrm{~L}_{4}\right]$ cubane clusters coordinated by different phosphine ligands $(\mathrm{L}=$ triphenylphosphine, tricyclopentylphosphine, and diphenylpropylphosphine). ${ }^{142}$ The cubane molecular structure of $\left[\mathbf{C u}_{\mathbf{4}} \mathbf{I}_{\mathbf{4}}\left(\mathbf{P P h}_{\mathbf{3}}\right)_{\mathbf{4}}\right]$ obtained from SCXRD (single-crystal X-ray diffraction) is presented in Figure 2a as example. The luminescence thermochromism is characterized by two emission bands namely HE (for High Energy) and LE (for Low Energy), whose relative intensity vary with the temperature. The thermochromism of $\left[\mathrm{Cu}_{4} \mathrm{I}_{4}\left(\mathrm{PPh}_{3}\right)_{4}\right]$ is presented in Figure 2b with a color change from green to purple from room temperature to $77 \mathrm{~K}$. DFT (Density Functional Theory) calculations permit to rationalize the luminescence thermochromism and to assign these two emission bands to two transitions involving molecular orbitals of different nature. The LE band was attributed to a transition implying a triplet state called ${ }^{3} \mathrm{CC}$ (Cluster Centered) which results from a combination of two transitions: one iodide-tocopper charge transfer (XMCT) and another involving the copper atoms ( $\mathrm{Cu} \mathrm{d} \rightarrow \mathrm{s})$. This transition takes place between an orbital of $\mathrm{Cu}-\mathrm{Cu}$ anti-bonding character (HOMO) and a vacant one having a 
$\mathrm{Cu}-\mathrm{Cu}$ bonding character (LUMO+24 for $\left.\left[\mathrm{Cu}_{4} \mathrm{I}_{4}\left(\mathrm{PPh}_{3}\right)_{4}\right]\right)$. Upon excitation, a significant relaxation thus occurs through $\mathrm{Cu}-\mathrm{Cu}$ bond shortening leading to an energetic stabilization of the ${ }^{3} \mathrm{CC}$ excited state. This LE emission band is therefore particularly dependent on the $\mathrm{Cu}-\mathrm{Cu}$ intramolecular interactions. The first experimental correlation between the $\mathrm{Cu}-\mathrm{Cu}$ distances and the emission wavelength was actually demonstrated on cubane clusters with thioether ligands by combining temperature-dependent SCXRD and luminescence experiments. ${ }^{143}$ The HE band, predominant at low temperature, was attributed to a copper,iodide $\rightarrow$ phosphine charge transfer transition denoted $(\mathrm{M}+\mathrm{X}) \mathrm{LCT}$ involving LUMOs based on $\pi^{*}$ orbitals of the ligands. The temperature variation of the two emission bands was explained by a thermal equilibrium between the two corresponding excited state $\left({ }^{3} \mathrm{CC}\right.$ and $\left.{ }^{3}(\mathrm{M}+\mathrm{X}) \mathrm{LCT}\right)$, as illustrated in Figure 2c. This result agrees with previous reports on the pyridine cluster ${ }^{144,145}$ but with a stronger coupling between the two excited states for the phosphines derivatives. Note that more accurate simulations of the luminescence thermochromism of phosphinebased clusters was recently achieved. ${ }^{123}$ Another striking difference with the N-based ligands lies on the $\mathrm{Cu}-\mathrm{Cu}$ intramolecular distances which are much longer in the phosphines case with mean distance values of $<3.1 \AA>$ versus $<2.7 \AA>.{ }^{146}$ They are also much longer than $2.8 \AA$ being twice the van der Waals radius of copper (I), ${ }^{147}$ which is usually considered as threshold for $\mathrm{d}^{10}-\mathrm{d}^{10}$ interactions to occur. $^{148}$ Therefore, even there is no strong cuprophilic interaction in the clusters with phosphine ligands, they display the $\mathrm{Cu}-\mathrm{Cu}$ bonding emissive state and the phenomenon of thermochromic luminescence, just as the pyridine derivatives do. The large shortening of the $\mathrm{Cu}$-Cu contacts upon excitation is moreover strong enough to significantly impact the emission properties. Finally, this study showed that phosphine-based $\left[\mathrm{Cu}_{4} \mathrm{I}_{4} \mathrm{~L}_{4}\right]$ clusters exhibit rich photoluminescence properties. Modulation of the thermochromism was later on demonstrated upon modification the electronic properties of the ligands. ${ }^{149}$

Luminescence mechanochromism. During the course of our investigations on these attracting luminophors, one cluster demonstrated completely original photoluminescence properties. Indeed, in addition to luminescence thermochromism, the cluster formulated $\left[\mathbf{C u}_{4} \mathbf{I}_{4}\left(\mathbf{P P h}_{2} \mathbf{C H}_{2} \mathbf{C H}=\mathbf{C H}_{2}\right)_{4}\right]$, exhibits mechanochromic luminescent properties. ${ }^{107}$ This phenomenon is characterized by a dramatic change of the emission from weak green to bright yellow, upon manual grinding of the crystalline compound (Figure 3). This contrasted effect with wavelength change from 530 to $580 \mathrm{~nm}$ and photoluminescence quantum yield (QY) increase from 2 to $14 \%$, is readily observable with the naked eye. The luminescence thermochromism of the cluster is also modified by the mechanical stress, the blue emission of the pristine compound at $77 \mathrm{~K}$ becoming purple. Reversibility is achieved by a thermal treatment at a relatively mild temperature $\left(\sim 100^{\circ} \mathrm{C}\right)$ or upon solvent exposure.

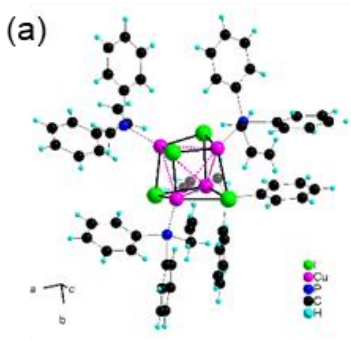

(b)

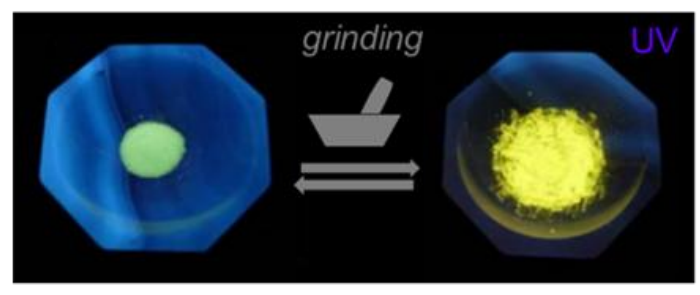

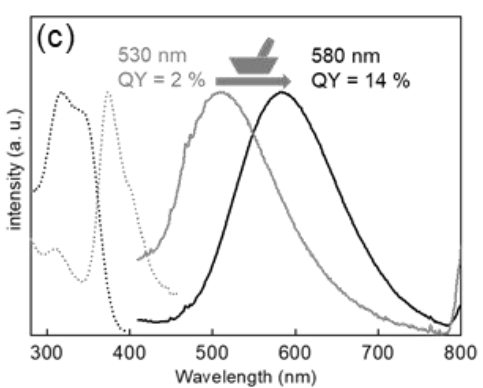
Figure 3. (a) Molecular structure of $\left[\mathrm{Cu}_{4} \mathrm{I}_{4}\left(\mathrm{PPh}_{2} \mathrm{CH}_{2} \mathrm{CH}=\mathrm{CH}_{2}\right)_{4}\right]$ from SCXRD. (b) Photos of crystalline powder
before and after manual grinding in a mortar, under UV irradiation. (c) Corresponding luminescence spectra before and after grinding at $\lambda_{\mathrm{ex}}=360 \mathrm{~nm}$. 
Liquid-state ${ }^{1} \mathrm{H}$ and ${ }^{31} \mathrm{P}$ NMR, UV-visible absorption and elemental analyses indicated that the chemical composition was unchanged and that the molecular structure of the cluster was not altered under the grinding process. The photoemission properties showed that the LE band of the pristine crystalline phase was of very low intensity and somehow quenched that was no longer the case after grinding. The ground phase has clearly a more classical luminescence behavior compared to the pristine one. Because the $\mathrm{LE}$ band depends on the $\mathrm{Cu}-\mathrm{Cu}$ interactions, as previously presented, modifications of these interactions within the cluster was suspected to occur under the mechanical stress. Indeed, because of the $\mathrm{Cu}-\mathrm{Cu}$ bonding character of the excited state, a shortening of the $\mathrm{Cu}-\mathrm{Cu}$ distances lowers the corresponding energy level resulting in an emission of weaker energy. This was coherent with the redshift observed upon grinding. This was confirmed by the exceptionally long intramolecular $\mathrm{Cu}-\mathrm{Cu}$ distances of the cluster $(<3.278(3) \AA>)$, with some even over $3.4 \AA$, compared with the values classically observed which can explain the seeming quenching of the LE band and the possibility of shortening. The long $\mathrm{Cu}-\mathrm{Cu}$ distances are attributed to constraints resulting from the crystal packing. Upon grinding, modification of the intermolecular interactions induces relaxation of the cluster core to a molecular structure with shorter intramolecular $\mathrm{Cu}-\mathrm{Cu}$ distances which subsequently regained classical luminescence properties. Suppression of the crystalline constraints were further confirmed by the similarities between the optical properties of the ground phase and those of the cluster in solution. Because no amorphous phase was detected by PXRD analysis but instead only a broadening of the diffraction peaks, the ground phase can be localized at local defects in the crystalline structure created upon grinding. This result contrasts with the commonly observed amorphous-to-crystalline transition reported for a large majority of mechanochromic compounds, with long-distance changes of the intermolecular interactions. The possibility to return to the pristine crystalline phase upon thermal treatment is in accordance to formation of structural defects in the cluster case. Note that precise characterization of these defects is rendered difficult because of their small proportion within the crystalline structure.

The mechanism investigation. A second cluster exhibiting luminescence mechanochromism was further revealed permitting a more comprehensive understanding of the phenomenon to be gained but above all, it generalized the mechanochromism phenomenon for this family of compounds. ${ }^{112} \mathrm{~A}$ particularly interesting feature of this second cluster formulated $\left[\mathrm{Cu}_{4} \mathbf{I}_{4}\left(\left(\mathbf{P P h}_{2}\left(\mathbf{C H}_{2}\right)_{2}\left(\mathbf{C H}_{3}\right)_{2} \mathbf{S i}\right)_{2} \mathbf{O}\right)_{2}\right]$, was its crystalline polymorphism, allowing straightforward establishment of structure-property relationships. Indeed, this cluster crystallizes in two crystalline forms, one green $(\mathbf{G})$ and the other yellow emissive (Y) (Figure 4a). Only the green polymorph exhibits mechanochromic luminescence properties with a ground phase $(\mathbf{C})$ presenting an emission band very similar to that of the yellow polymorph (Figure $4 \mathrm{~b}$ ). The reversibility is achieved upon solvent treatment.
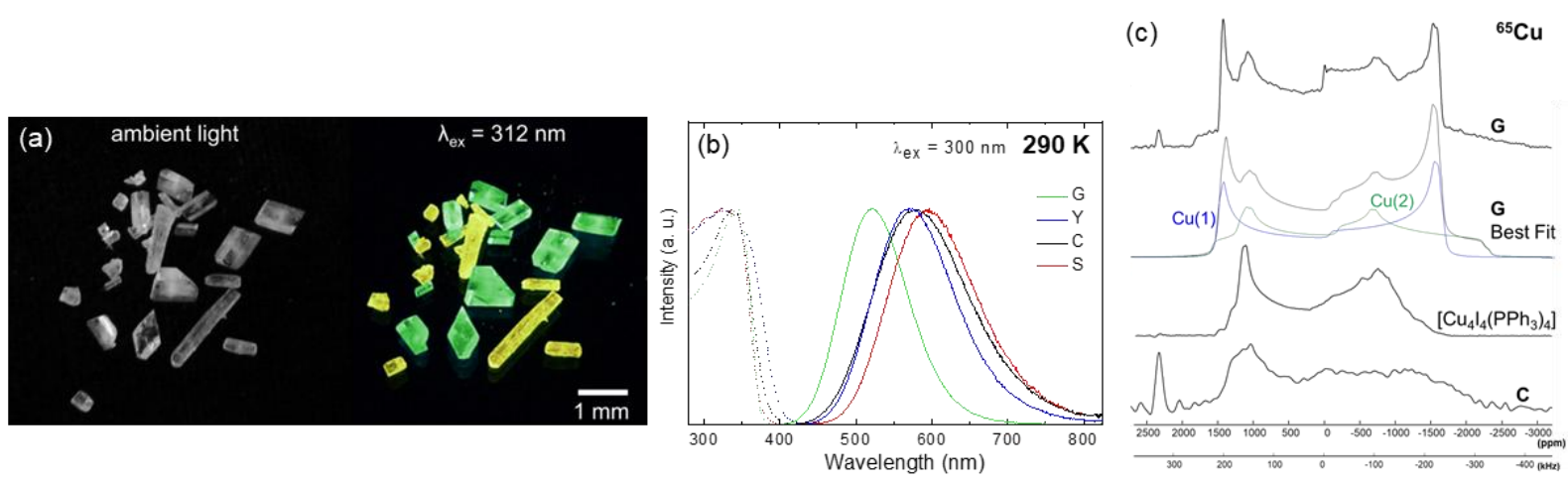

Figure 4. (a) Photos of polymorphic crystals of $\left[\mathrm{Cu}_{4} \mathrm{I}_{4}\left(\left(\mathrm{PPh}_{2}\left(\mathrm{CH}_{2}\right)_{2}\left(\mathrm{CH}_{3}\right)_{2} \mathrm{Si}\right)_{2} \mathrm{O}\right)_{2}\right](\mathbf{G}$ and $\mathbf{Y})$ under ambient light and UV at room temperature. (b) Luminescence spectra of $\mathbf{G}, \mathbf{Y}$ and $\mathbf{C}$ at $290 \mathrm{~K}, \mathbf{S}$ corresponds to the cluster in dichloromethane solution. (c) Solid-state static ${ }^{65} \mathrm{Cu}$ NMR spectra of $\mathbf{G},\left[\mathrm{Cu}_{4} \mathrm{I}_{4}\left(\mathrm{PPh}_{3}\right)_{4}\right]$ and $\mathbf{C}$. The best 
fit of the DFT simulated $\mathbf{G}$ spectrum with the individual contributions of $\mathrm{Cu}(1)$ and $\mathrm{Cu}(2)$ sites. The peaks at $2400 \mathrm{ppm}$ are the copper signal of the NMR coil.

Analysis of the molecular structures of the two polymorphs revealed shorter $\mathrm{Cu}-\mathrm{Cu}$ distances for the yellow luminescent cluster $\mathbf{Y}(<\mathrm{Cu}-\mathrm{Cu}\rangle=2.885$ (1) $\AA)$ compared to its green counterpart $\mathbf{G}(<\mathrm{Cu}-\mathrm{Cu}\rangle$ $=3.104$ (1) $\AA$ ), while other geometric characteristics are comparable. This result permit to confirm the correlation between the emission wavelength at room temperature (LE band) and the $\mathrm{Cu}-\mathrm{Cu}$ distances. This correlation provided information about the ground phase since its emission properties are similar to those of Y. PXRD analysis showed that a crystalline-to-amorphous transition occurs in contrast to the previous mechanochromic cluster. The ground phase is therefore no longer minor allowing to carry out solid-state NMR study. The ${ }^{31} \mathrm{P}$ NMR spectra are different for the two polymorphs in agreement with different molecular structures. The spectrum of the ground compound $(\mathbf{C})$ is in agreement with an almost complete amorphization with a chemical shift different from that of the crystalline phase, which highlights the modification of the environment of phosphorus atoms under the grinding process. The less classical ${ }^{65} \mathrm{Cu}$ solid-state NMR analysis was conducted to get information on the $\mathrm{Cu}-\mathrm{Cu}$ interactions within the amorphous ground phase. The ${ }^{65} \mathrm{Cu}$ spectra of $\mathbf{C}$ presents a signal similar to that of $\left[\mathrm{Cu}_{4} \mathrm{I}_{4}\left(\mathrm{PPh}_{3}\right)_{4}\right]$ (close geometrical parameters with similar $\mathrm{Cu}-\mathrm{Cu}$ distances to $\mathbf{Y}$ ), which is different from that of the $\mathbf{G}$ pristine form. The latter could have been simulated by DFT and is indeed composed of two contributions: one corresponding to $\mathrm{Cu}$ atoms involved in short and another in long $\mathrm{Cu}-\mathrm{Cu}$ distances (Figure 4c). The grinding thus modifies the copper environment with a shortening of the $\mathrm{Cu}$ $\mathrm{Cu}$ distances leading to a more symmetrical $\left[\mathrm{Cu}_{4} \mathrm{I}_{4}\right]$ core. This study was therefore in perfect agreement with the previous results indicating modification of the cuprophilic interactions within the cluster under the mechanical effect, generating consequently changes of the luminescence properties. These results were further confirmed by the study of another series of crystalline polymorphs of such cubane copper iodide clusters. ${ }^{113}$

Even if the $\mathrm{Cu}-\mathrm{Cu}$ interactions appeared to be the main culprits for the luminescence mechanochromism of the copper iodide clusters, no direct evidence of their modification under the effect of mechanical stress was obtained so far. In order to get information on the molecular structure of the cluster within the mechanically altered phase, we performed in situ measurements of luminescence and SCXRD, under controlled hydrostatic pressure using a Diamond Avil Cell (DAC) ${ }^{150}$ Such experiments allowed to directly correlate the structural changes induced by the pressure, with the observed emission properties.

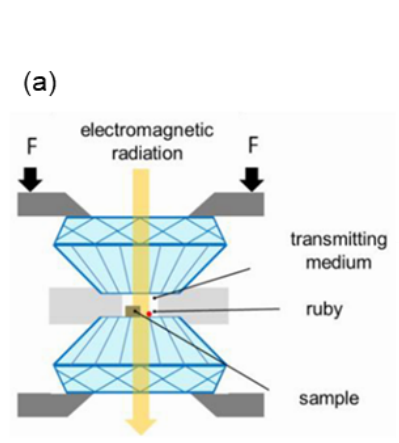

(b)

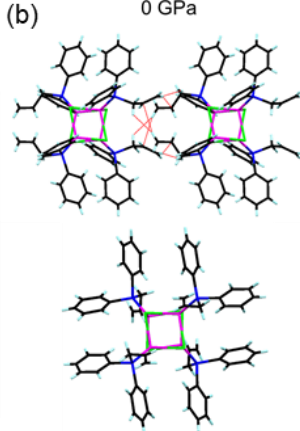

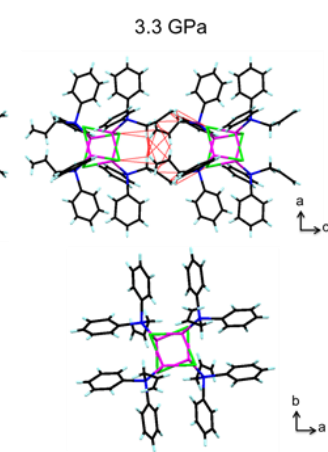

Figure 5. (a) Schematic representation of the DAC pressure cell. (b) Short contacts $(<2.8 \AA)$ in red lines and molecular structure of the cluster at 0 and $3.3 \mathrm{GPa}$. (c) Relative variation of selected intramolecular distances (circles) and angles (squares) of the cluster at different pressures.

A single crystal of the $\left[\mathbf{C u}_{4} \mathbf{I}_{4}\left(\mathbf{P P h}_{2} \mathbf{C H}_{2} \mathbf{C H}=\mathbf{C H}_{2}\right)_{4}\right]$ cluster was thus studied over the 0-4 GPa pressure range (Figure 5a). Upon increasing the pressure, the emission band undergoes a redshift 
similar to the grinding effect. No phase transition was detected, the pressure causes compression of the system with $20 \%$ reduction of the cell volume, a typical value for 'soft' molecular compounds. This compression increases the number of intercluster interactions and induces substantial modifications of the molecular structure of the cluster and in particular of its $\left[\mathrm{Cu}_{4} \mathrm{I}_{4}\right]$ core (Figure $5 \mathrm{~b}$ ). Variations of different bond distances and angles over the pressure range (Figure 5c), indicate that while the $\mathrm{Cu}-\mathrm{P}$ and $\mathrm{Cu}-\mathrm{I}$ bonds present a limited change ( 1 and $2 \%$, respectively), the $\mathrm{Cu}-\mathrm{Cu}$ distances are largely shortened $(-13 \%)$ from $<3.278(2) \AA>$ to $<2.837(2) \AA>$ which then become comparable to the sum of the van der Waals radii of copper (I) (2.8 $\AA$ ). A large geometric modification of the cluster core thus occurred with a contraction of the volume of the $\mathrm{Cu}_{4}$ tetrahedron (-35\%) while that of $\mathrm{I}_{4}$ shows only a small variation $(+7 \%)$. These results highlight the flexibility of the cluster core with the $\mathrm{Cu}-\mathrm{Cu}$ bonds endorsing most of the mechanical stress. By reducing in a controlled manner the intramolecular $\mathrm{Cu}-\mathrm{Cu}$ distances, the redshift of the emission observed under mechanical stress can therefore be correlated to $\mathrm{Cu}-\mathrm{Cu}$ distances shortening. This conclusion was in a perfect agreement with previous analyses and permit to definitively ascribe the mechanochromic luminescence phenomenon of copper iodide clusters to an increase of cuprophilic interactions. In opposite to several other studies, ${ }^{151}$ the effects of the isotropic pressure (DAC) are similar to those of the anisotropic stress (grinding) in the present case. This difference can be explained by different mechanochromism mechanisms. Indeed, for the clusters, the mechanism involves changes at the intramolecular level while the others are based on modifications of intermolecular interactions with for instance, formation of excimers ${ }^{152}$ and changes of intermolecular $\mathrm{Au}-\mathrm{Au}$ interactions. ${ }^{153}$

From previous results, the pristine crystal packing of the cluster is a crucial parameter in the mechanochromism mechanism by creating a metastable state. Indeed, it is the specific inter-cluster interactions that impose constraints on the molecular structure of the cluster leading to a distorted geometry having relatively long $\mathrm{Cu}-\mathrm{Cu}$ distances. As schematized in Figure 6, under the action of grinding, modification of the intermolecular interactions allows relaxation of the molecular structure towards a more contracted geometry with shorter $\mathrm{Cu}-\mathrm{Cu}$ distances. The mechanochromism thus results from a subtle competition between crystal packing and intramolecular interactions. This competition is illustrated by crystalline polymorphs presenting different $\mathrm{Cu}-\mathrm{Cu}$ interactions, encountered for several clusters of this family. The importance of the intermolecular interactions was subsequently demonstrated by a comparative study conducted between the first mechanochromic cluster and its analogue coordinated by the saturated version of the ligand $\left(\mathrm{PPh}_{2} \mathrm{CH}_{2} \mathrm{CH}=\mathrm{CH}_{2}\right.$ vs $\left.\mathrm{PPh}_{2} \mathrm{CH}_{2} \mathrm{CH}_{2} \mathrm{CH}_{3}\right) .{ }^{116}$ Differences in the intermolecular interactions in the molecular arrangements is the only explanation for the lack of mechanochromic properties of the latter. 


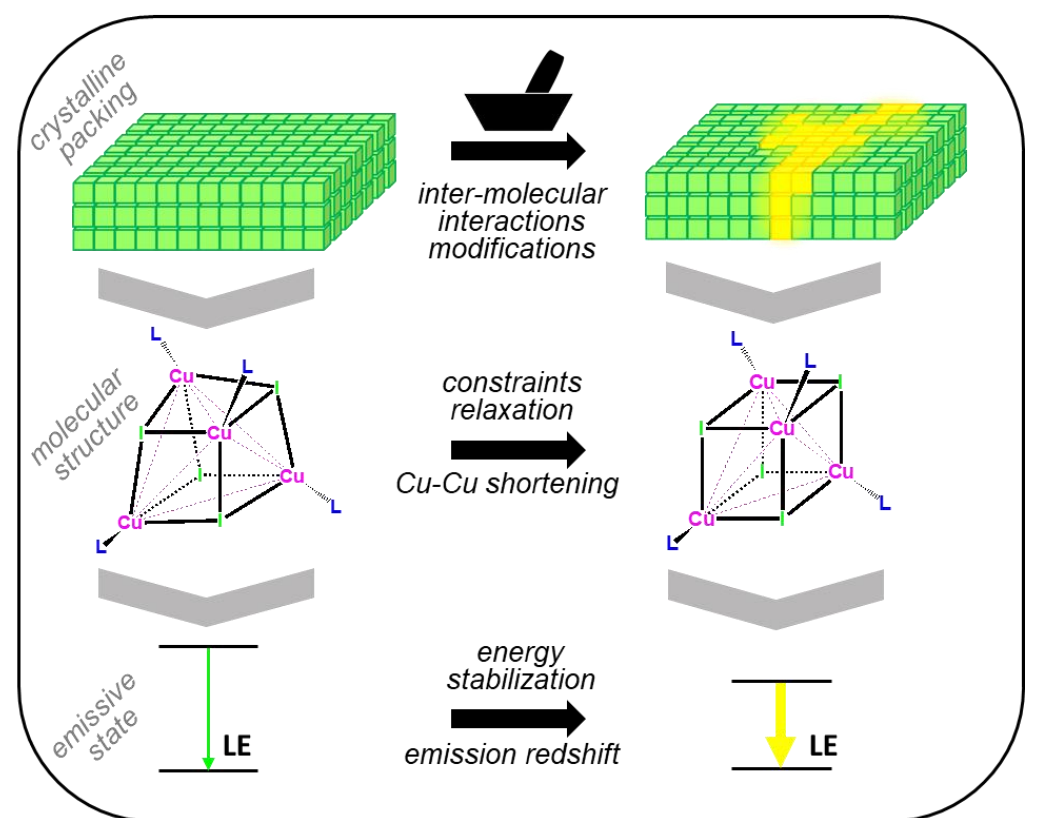

Figure 6. Schematic representation of the mechanism of the luminescence mechanochromism phenomenon of cubane $\left[\mathrm{Cu}_{4} \mathrm{I}_{4} \mathrm{~L}_{4}\right]$ copper iodide clusters.

A similar mechanism based on modulation of the $\mathrm{Cu}-\mathrm{Cu}$ distances has been also reported for explaining the luminescent mechanochromic properties of several other cubane copper iodide clusters. In particular, the group of M.-C. Hong described the mechanochromism of $\left[\mathrm{Cu}_{4} \mathrm{I}_{4}\left(\mathrm{PPh}_{2}\left(\mathrm{CH}_{2}\right)_{2} \mathrm{CO}_{2} \mathrm{H}\right)_{4}\right]$ whose mechanism is ascribed to $\mathrm{Cu}-\mathrm{Cu}$ distances shortening associated with solvent release. ${ }^{109}$ Perturbation of the $\mathrm{Cu}-\mathrm{Cu}$ interactions were also involved in the case of $\left[\mathrm{Cu}_{4} \mathrm{I}_{4}\left(\mathrm{PPh}_{2} \mathrm{C}_{6} \mathrm{H}_{4}-\right.\right.$ $\left.\left.\mathrm{N}\left(\mathrm{CH}_{3}\right)_{2}\right)_{4}\right] .{ }^{110}$ More recently, changes in intramolecular $\mathrm{Cu}-\mathrm{Cu}$ interactions were involved in the mechanochromism of $\left[\mathrm{Cu}_{4} \mathrm{I}_{4}(3 \text {-pmbtd })_{4}\right]$ coordinated by a bidentate $\mathrm{N}$-based ligand, even if there are not particularly long in the pristine crystalline phase. ${ }^{121}$ Reconsideration of the involvement of the $\mathrm{Cu}$ $\mathrm{Cu}$ interactions in the mechanochromism was argued by Yang et al., based on the very long distances

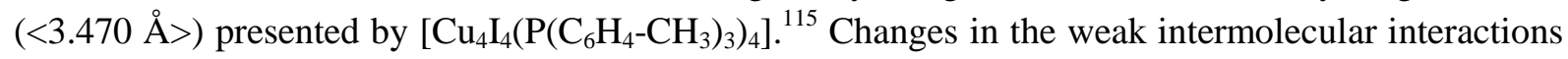
was instead suggested for explaining the observed emission redshift upon grinding. However, it should be kept in mind that even if in the pristine state the $\mathrm{Cu}-\mathrm{Cu}$ distances are long enough to prevent cuprophilic interaction, important shortening can occur under mechanical forces that can impact the photoluminescence properties. Note that changes in intra and intermolecular $\mathrm{Cu}-\mathrm{Cu}$ interactions was even pointed for explaining the luminescence mechanochomism of copper nanoclusters. ${ }^{154}$

Towards the predictability of the mechanochromic properties. The future development of mechanochromic luminescent materials will certainly benefit from their rational design. However, despite the large number of reported mechanochromic compounds, the predictability of their mechanochromic properties remains a great challenge. Regarding the cubane clusters, long intramolecular $\mathrm{Cu}-\mathrm{Cu}$ distances appeared to be one of the necessary condition for presenting mechanochromic properties. The $\left[\mathbf{C u}_{4} \mathbf{I}_{\mathbf{4}}\left(\mathbf{P P h}_{3}\right)_{4}\right]$ cluster was known to present two crystalline polymorphs, $\mathbf{a}$ and $\mathbf{b}$, having different luminescence properties and structural features. ${ }^{155,156}$ Indeed, $\mathbf{a}$ is yellow luminescent $\left(\lambda_{\max }=545 \mathrm{~nm}\right)$ with relatively short $\mathrm{Cu}-\mathrm{Cu}$ distances $(<2.968(1) \AA>$ \ $)$ compared with the $\mathbf{b}$ green emissive polymorph $\left(\lambda_{\max }=520 \mathrm{~nm}\right)$ displaying longer distances $(<3.069(2) \AA>$ ). We thus postulated that only the green polymorph should be mechanochromic. We effectively proven it experimentally (Figure 7). ${ }^{122}$ Characterizations indicated a crystal-to-amorphous transition for $\mathbf{b}$ and a ground phase presenting spectroscopic similarities with the non mechanochromic polymorph a. Structural analyses under controlled pressure (DAC) additionally confirmed the $\mathrm{Cu}-\mathrm{Cu}$ bonds 
flexibility and their shortening. This study permit to ascertain the mechanochromic mechanism based on an increase of $\mathrm{Cu}-\mathrm{Cu}$ interactions under mechanical stress. Above all, this study demonstrated that mechanochromic properties can be, at a certain degree, predicted for this family of compounds that constitutes a step further toward their rational design.
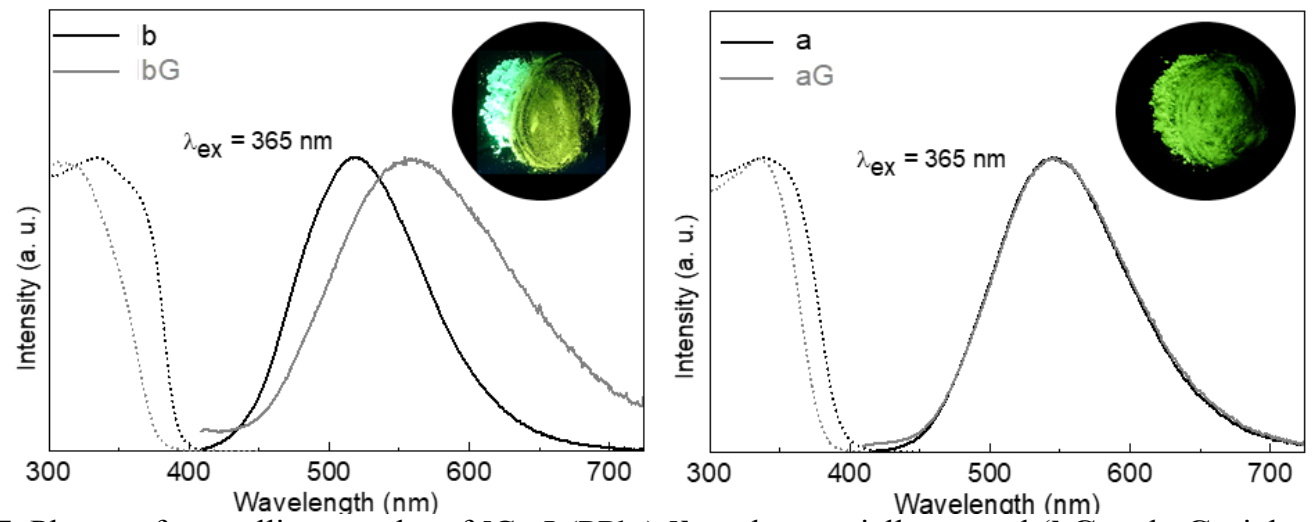

Figure 7. Photos of crystalline powder of $\left[\mathrm{Cu}_{4} \mathrm{I}_{4}\left(\mathrm{PPh}_{3}\right)_{4}\right] \mathbf{b}$ and $\mathbf{a}$, partially ground (bG and $\mathbf{a G}$, right side) under UV irradiation (365 nm - UV lamp) and corresponding solid-state luminescence spectra with normalized emission spectra in solid line $\left(\lambda_{\mathrm{ex}}=365 \mathrm{~nm}\right)$ and excitation ones in dotted lines recorded at $\lambda_{\max }$ of emission, at room temperature.

The luminescence mechanochromism of organic molecules are in several cases associated to their AIE properties (Aggregation Induced Emission). An AIE compound is characterized by a weak emission in solution while an intense emission is displayed when aggregated in solid-state due to restriction of molecular motions. ${ }^{157}$ Because of multiple conformations, AIE organic molecules generally exhibit disordered and low density arrangements in the solid-state, facilitating their transformation between different molecular arrangements. This characteristic leads to an increased sensitivity to external stimuli and in particular to mechanical stress. Therefore, many AIE molecules were reported to be mechanochromic ${ }^{158-160}$ leading to the appealing perspective of the rational design of luminescent mechanochromic materials. Regarding the mechanochromic luminescence properties of copper iodide clusters and their structural flexibility, it seemed interesting to precisely evaluate their AIE properties. We have thus studied the AIE properties of two different $\left[\mathrm{Cu}_{4} \mathrm{I}_{4} \mathrm{~L}_{4}\right]$ copper iodide clusters and the correlation with their luminescence mechanochromism properties. ${ }^{161}$ The two clusters are formulated $\left[\mathrm{Cu}_{4} \mathbf{I}_{4}\left(\mathbf{P P h}_{2}\left(\mathbf{C}_{6} \mathbf{H}_{4}-\mathbf{C H}_{2} \mathrm{OH}\right)\right)_{4}\right]$ and $\left[\mathrm{Cu}_{4} \mathbf{I}_{4}\left(\mathbf{P P h}_{2} \mathbf{C H}_{2} \mathbf{C H}_{2} \mathbf{C H}_{3}\right)_{4}\right]$, and only the first one is mechanochromic, as presented below. As shown is Figure 8, the AIE properties of the two clusters are characterized by an increase of the emission intensity of their solution upon aggregation induced by the addition of water acting as poor solvent. The two clusters exhibit different AIE behaviors with a more gradual increase of the emission intensity for $\left[\mathrm{Cu}_{4} \mathrm{I}_{4}\left(\mathrm{PPh}_{2} \mathrm{CH}_{2} \mathrm{CH}_{2} \mathrm{CH}_{3}\right)_{4}\right]$ while it appears more abruptly for the other one. 

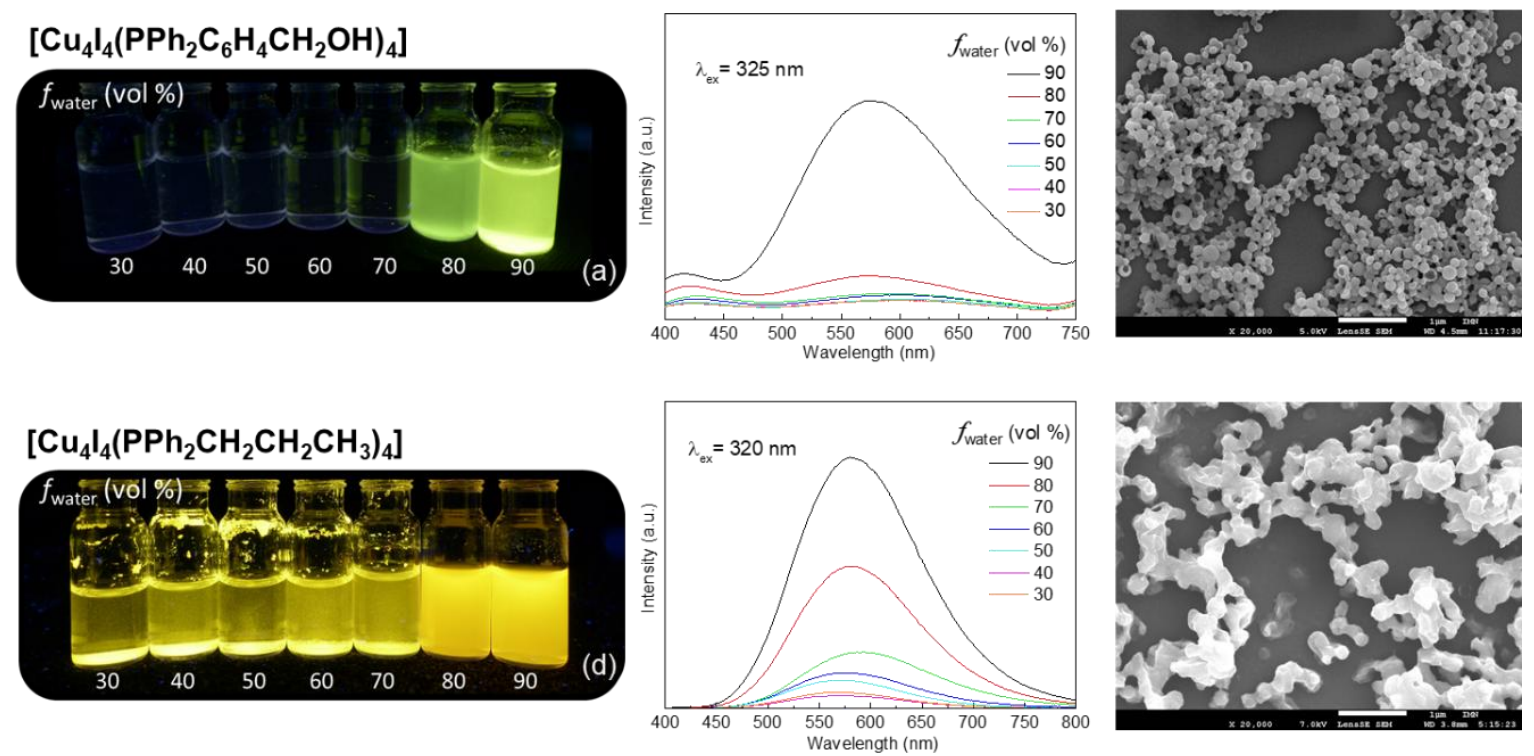

Figure 8. Photos of $\mathrm{THF} / \mathrm{H}_{2} \mathrm{O}$ and acetone/ $\mathrm{H}_{2} \mathrm{O}$ suspensions of $\left[\mathrm{Cu}_{4} \mathrm{I}_{4}\left(\mathrm{PPh}_{2}\left(\mathrm{C}_{6} \mathrm{H}_{4} \mathrm{CH}_{2} \mathrm{OH}\right)\right)_{4}\right]$ and $\left[\mathrm{Cu}_{4} \mathrm{I}_{4}\left(\mathrm{PPh}_{2} \mathrm{CH}_{2} \mathrm{CH}_{2} \mathrm{CH}_{3}\right)_{4}\right]$, respectively, with the water fraction $\left(f_{\mathrm{w}}\right)$ ranging from 30 to 90 vol\%, under UV $(365 \mathrm{~nm})$ at room temperature. Corresponding emission spectra and emission intensity as a function of $f_{\mathrm{w}}$. SEM images of the particles formed in solutions with $f_{\mathrm{w}}=90 \%$.

Characterizations of the suspensions show the formation of relatively stable particles of $250 \mathrm{~nm}$ mean diameter with a main amorphous character (Figure 8). These particles exhibit the luminescence thermochromism of the corresponding clusters. The mechanism at the origin of the AIE properties of the clusters can be attributed to suppression of non-radiative decays once aggregated, in accordance with studies on organic molecules and complexes. This result agrees with the nature of the emission band of the cluster. Indeed, as previously mentioned, the excited triplet state of the LE band presents large relaxation due to intramolecular distortions which may result in an efficient non-radiative decay pathway. This effect thus explains the low intensity of the emission of the cluster in solution. On the other hand, the rigidity of the solid-state limiting molecular motions favors radiative processes. The AIE properties of the clusters can be related to the ligands with in particular the rotation of the phenyl groups. The correlation between the AIE properties and the mechanochromism of the two clusters is not, however, straightforward. Indeed, only one cluster is mechanochromic while the two clusters present AIE properties. Nevertheless, a relation between AIE properties and mechanochromism can be established on the basis of the formation of solid-state arrangements sensitive to mechanical stress. Indeed, the molecular structure of these pseudo-tetrahedral clusters having bulky ligands with flexible substituents, leads to crystal packing of low density. However, as illustrated by the nonmechanochromic cluster, the formation of a relatively soft molecular arrangement is not the only requirement to exhibit luminescence mechanochromism, the molecular structure of the cluster must itself be mechanical stress sensitive.

Deepening of the mechanochromism mechanism. As previously shown, the study of the mechanochromism mechanism is generally arduous due to the difficulty in directly characterizing the structural changes within the mechanically altered phase. Indeed, in opposite to outstanding examples for which the application of mechanical forces induces a crystal-to-crystal transformation, ${ }^{162}$ a partial crystal-to-amorphous transition generally occurs or even only local defects are formed, as for some copper iodide clusters. The characterization of an amorphous phase embedded within a crystalline phase is relatively complicated. In this context, we managed to synthesize a luminescent 
mechanochromic cluster that can form upon melting a fully amorphous state, representing the ultimate mechanically altered state. ${ }^{123}$

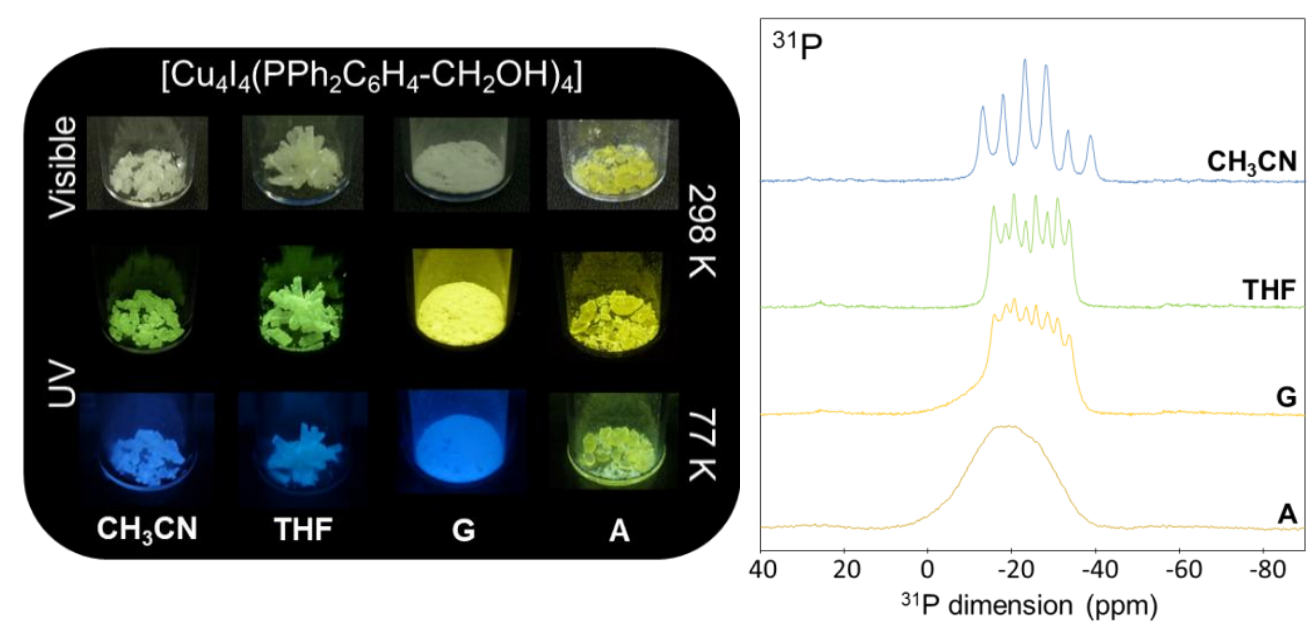

Figure 9. Photos of the four studied states of $\left[\mathrm{Cu}_{4} \mathrm{I}_{4}\left(\mathrm{PPh}_{2} \mathrm{C}_{6} \mathrm{H}_{4}-\mathrm{CH}_{2} \mathrm{OH}\right)_{4}\right]$ : $\mathbf{C H} \mathbf{C N}, \mathbf{T H F}, \mathbf{G}$ and $\mathbf{A}$ under visible light and UV excitation, at 298 and $77 \mathrm{~K}$. Corresponding solid-state ${ }^{31} \mathrm{P}$ CPMAS NMR spectra.

In addition to an amorphous state, this cluster of $\left[\mathbf{C u}_{4} \mathbf{I}_{4}\left(\mathbf{P P h}_{2} \mathbf{C}_{6} \mathbf{H}_{4}-\mathbf{C H}_{2} \mathbf{O H}\right)_{4}\right]$ formula can form two crystalline polymorphs upon recrystallization in $\mathrm{CH}_{3} \mathrm{CN}$ and THF solvents. The comparative study of this cluster in four different states: crystalline $\mathbf{T H F}$ and $\mathbf{C H}_{3} \mathbf{C N}$, ground $\mathbf{G}$ and amorphous $\mathbf{A}$ (Figure 9), was therefore carried out along with DFT calculations to rationalize the experimental results. The luminescence mechanochromism properties of this cluster are characterized by a redshift of the emission from green to yellow (540 to $560 \mathrm{~nm}$ ), with an incomplete crystal-to-amorphous transition. The ${ }^{63} \mathrm{Cu}$ and ${ }^{31} \mathrm{P}$ solid-state NMR spectra confirmed this partial crystal-to-amorphous transition with a signal for $\mathbf{G}$ with two contributions, one from an intact crystalline phase and the other from an amorphous phase. Using the NMR signature of $\mathbf{A}$, the quantification of the amorphous phase within $\mathbf{G}$ was possible and permit to evaluate the proportion of mechanically modified phase at $25 \%$. This result provides a quantitative response regarding the mechanochromism mechanism, rarely reported. IR and Raman characterizations were conducted supported by DFT spectra simulations. In particular, spectra were recorded in the low frequency domain $\left(45-650 \mathrm{~cm}^{-1}\right)$ where the vibrations of the inorganic $\left[\mathrm{Cu}_{4} \mathrm{I}_{4}\right]$ cluster core occur. Analyses of the four states showed that while the signal of the ligand is not modified, changes are observed the $\mathrm{Cu}-\mathrm{I}$ and $\mathrm{Cu}-\mathrm{Cu}$ bonds vibrations. Moreover, the signal of $\mathbf{G}$ presents similarities with that of $\mathbf{A}$ which is closed to the $\mathbf{C H}_{3} \mathbf{C N}$ polymorph having a more symmetrical cluster core. In this study, the characterization of the fully amorphous phase, being the ultimate state of grinding, allowed to get further into the understanding of the associated mechanism. $\mathrm{Cu}-\mathrm{Cu}$ interactions are still involved in the present case but this work, combining intimately experience and theory, shows that the geometry of the cluster core must be considered as a whole.

The mechanochromic luminescent effect was so far reported upon grinding crystalline powders. Liquid-crystalline compounds being softer so more easily altered by mechanical forces but still organized, attracted our attention. In order to confer mesomorphic properties to copper iodide clusters, the functionalization of the $\left[\mathrm{Cu}_{4} \mathrm{I}_{4}\right]$ cluster core was realized with a phosphine ligand (L) bearing the cyanobiphenyl (CBP) moiety, a well-known mesomorphic promoter (Figure 10a). ${ }^{117}$ 
(a)
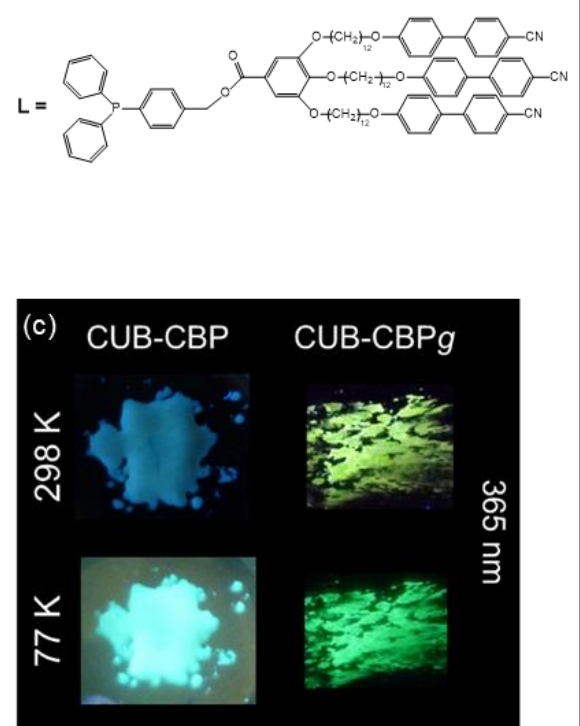

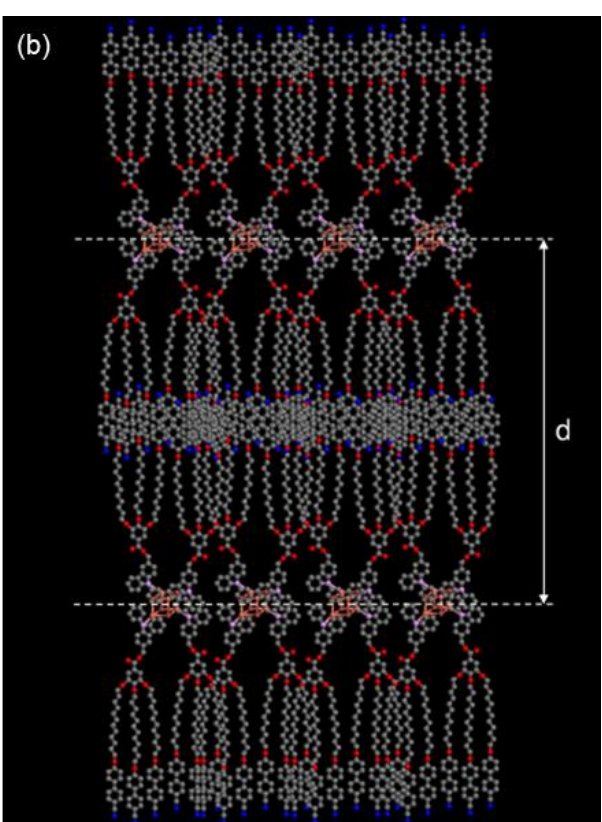

Figure 10. (a) Schematic representation of the cluster functionalized with a CBP ligand, namely CUB-CBP. (b) Suggested model of molecular organization of the lamellar smectic mesophase. (c) Photos of the pristine and ground (g) CUB-CBP cluster under UV excitation at 298 and $77 \mathrm{~K}$.

The functionalized cluster (CUB-CBP) exhibits mesomorphic properties with the formation of a lamellar smectic A phase above the glass transition $\left(24{ }^{\circ} \mathrm{C}\right)$, that is retained in the solid-state upon cooling. In the suggested model of molecular organization in this smectic phase, the ligands are two by two located on either side of the $\left[\mathrm{Cu}_{4} \mathrm{I}_{4}\right]$ cluster core with a perpendicular alignment to the layers (Figure 11b). A molecular segregation is clearly observed with inorganic and organic layers. The CBP groups interpenetration must be responsible for the mesomorphic properties. CUB-CBP in the smectic phase presents two emission bands at room temperature. The one at $400 \mathrm{~nm}$ is attributed to the CBP groups and the second one at $515 \mathrm{~nm}$ to the LE band. In addition to excitation-dependent emission, luminescence thermochromism is also displayed by this cluster. The luminescence mechanochromism for its part is characterized by a redshift of the LE emission band from blue to yellow-green from 515 to $540 \mathrm{~nm}$ (Figure 11c). According to SAXS analysis, the grinding induces a transition from the solid smectic phase to a less organized one. In accordance to previous results, the mechanochromism is attributed to an increase of the $\mathrm{Cu}-\mathrm{Cu}$ interactions within the $\left[\mathrm{Cu}_{4} \mathrm{I}_{4}\right]$ cluster core. However, in opposite to other mechanochromic clusters, the mechanochromism is in this case spontaneously reversible after few hours at room temperature. This effect can be explained by the softer matter allowing spontaneous reconstruction. This rare example of a mesomorphic and mechanochromic luminescent compound opens promising perspectives with respect to the wide range of external stimuli impacting liquid-crystal structural arrangements and the related properties.

Other polymetallic copper iodide clusters. Copper iodide clusters with geometries different from the cubane one were further proved to exhibit luminescence mechanochromism as well. One of them is actually an isomer of the cubane form which has a chair geometry. ${ }^{118}$ Upon grinding, this compound formulated $\left[\mathbf{C u}_{4} \mathbf{I}_{\mathbf{4}}\left(\mathbf{P P h}_{3}\right)_{4}\right] \cdot \mathbf{2} \mathbf{C H C l}_{3}$, displays a contrasted emission change from blue to yellow associated with a large redshift of $100 \mathrm{~nm}$ (Figure 11). Its pseudo-polymorph of $\left[\mathbf{C u}_{4} \mathbf{I}_{4}\left(\mathbf{P P h}_{3}\right)_{4}\right] \cdot \mathbf{2 C H}_{2} \mathbf{C l}_{2}$ formula exhibits an even more contrasted mechanochromic effect of OFFON type. 


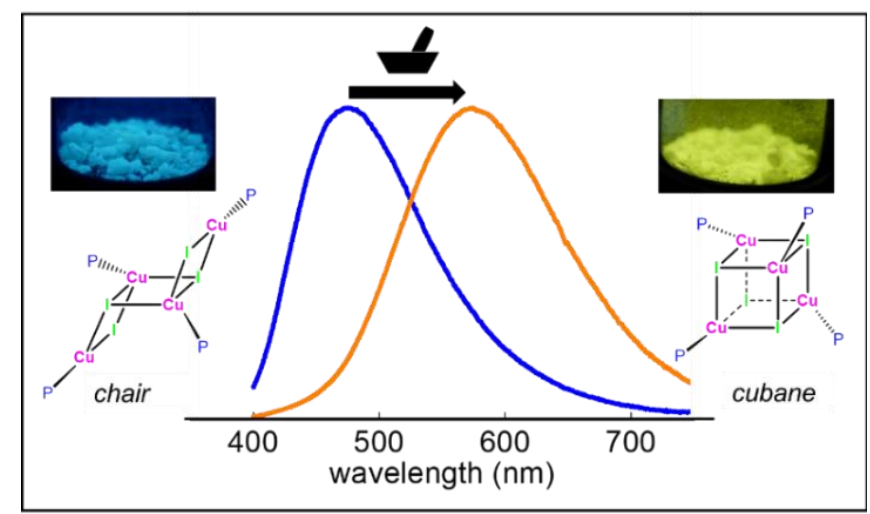

Figure 11. Mechanochromism of $\left[\mathrm{Cu}_{4} \mathrm{I}_{4}\left(\mathrm{PPh}_{3}\right)_{4}\right] \cdot 2 \mathrm{CHCl}_{3}$ with photos of the powder before and after grinding and associated emission spectra with representations of the two chair and cubane isomers.

The photophysical properties of the ground phases have many similarities with those of the cubane isomer and in particular they present its characteristic luminescence thermochromism. According to structural and optical data associated to DFT calculations, the mechanism of the mechanochromism has been attributed to a chair $\rightarrow$ cubane structural isomerization in the solid-state. This isomerization occurs by closing the open chair structure to the cubane one which has two more $\mathrm{Cu}-\mathrm{I}$ bonds and three additional $\mathrm{Cu}-\mathrm{Cu}$ interactions. The blue emission coming from the ${ }^{3}(\mathrm{X}+\mathrm{M}) \mathrm{LCT}$ excited state of the chair isomer is then replaced upon grinding, by the yellow LE emission band of the cubane. This mechanically-induced isomerization is corroborated by the very close thermodynamic stability of the two isomers evaluated by DFT. However, this isomerization occurs because the crystalline structure allows it. Indeed, the intermolecular interactions in the structure are relatively weak and the labile solvent molecules in the structure (partially lost upon grinding) give the cluster enough freedom to change its geometry. The lack of mechanochromic properties for another chair cluster formulated $\left[\mathrm{Cu}_{4} \mathrm{I}_{4}\left(\mathrm{PPh}_{2}-\mathrm{C}_{6} \mathrm{H}_{4} \mathrm{CO}_{2} \mathrm{H}\right)_{4}\right]$ can be explained by the strong cohesion of its crystalline structure based on a robust hydrogen bonds network. This unprecedented mechanism based on a solid-state isomerization indicates that the $\mathrm{Cu}-\mathrm{Cu}$ interactions are no longer directly involved. A related mechanism has been reported by Kobayashi et al., with a rhombic $\left[\mathrm{Cu}_{2} \mathrm{I}_{2}\right] \rightarrow$ cubane $\left[\mathrm{Cu}_{4} \mathrm{I}_{4}\right]$ structural dimerization involving a switch between the ${ }^{3}(\mathrm{M}+\mathrm{X}) \mathrm{LCT}$ and ${ }^{3} \mathrm{CC}$ excited states. ${ }^{119}$ In addition to clusters of chair geometry, few other mechanochromic copper iodide clusters were also reported. A double cubane formulated $\left[\mathrm{Cu}_{8} \mathrm{I}_{8}\left(\mathrm{PPh}_{2} \mathrm{C}_{6} \mathrm{H}_{4}-\mathrm{N}\left(\mathrm{CH}_{3}\right)_{2}\right)_{6}\right]^{111}$ was described as well as the butterfly shaped $\left[\mathrm{Cu}_{4} \mathrm{I}_{4}\left(\mathrm{PPh}_{2} \text { py }\right)_{2}\right]$ cluster. ${ }^{120}$ Two isostructural coordination polymers based on the $\left[\mathrm{Cu}_{6} \mathrm{I}_{6}\right]$ cluster core with pyridine-based ligands $\left(\mathrm{CH}_{3} \mathrm{Si}\left({ }^{3} \mathrm{Py}\right)_{3}\right)$ display mechanochromic properties too. ${ }^{114}$ In the three latter examples, the mechanochromic mechanism was ascribed to $\mathrm{Cu}-\mathrm{Cu}$ distances changes. This is different for the dinuclear $\left[\mathrm{Cu}_{2} \mathrm{I}_{2} \mathrm{~L}_{4}\right]$ and $\left[\mathrm{Cu}_{2} \mathrm{I}_{4}\right]^{2-}$ complexes whose mechanochromic properties were attributed to modifications of intermolecular interactions, an expected result from their unique $\mathrm{Cu}-\mathrm{Cu}$ interaction. ${ }^{98,100}$

Potential applicability. For practical applications of mechanical sensing, the design of thin films is more suitable compared with powdered luminescent mechanochromic compound with no mechanical strength. In parallel to the understanding the mechanochromism mechanism, we took advantage of the contrasted luminescent mechanochromic properties of $\left[\mathbf{C u}_{4} \mathbf{I}_{4}\left(\mathbf{P P h}_{2} \mathbf{C H}_{2} \mathbf{C H}=\mathbf{C H}_{2}\right)_{4}\right]$ cluster to develop mechanically-responsive films. ${ }^{116}$ These films were synthesized by deposition of a solution of the cluster on a glass substrate (thickness $\sim 150 \mathrm{~nm}$ ). The X-ray diffraction analysis of these yellow emissive films, revealed low crystallinity with crystalline domains of small coherence length $(\xi \sim 6$ $\mathrm{nm}$ ). This agree with the very smooth film surface observed by SEM analysis (Figure 12). After 
annealing at $100{ }^{\circ} \mathrm{C}$, the films are no longer emissive and narrow diffraction peaks were recorded indicating recrystallization. The crystallites of micrometric size could actually be observed on the corresponding SEM images.

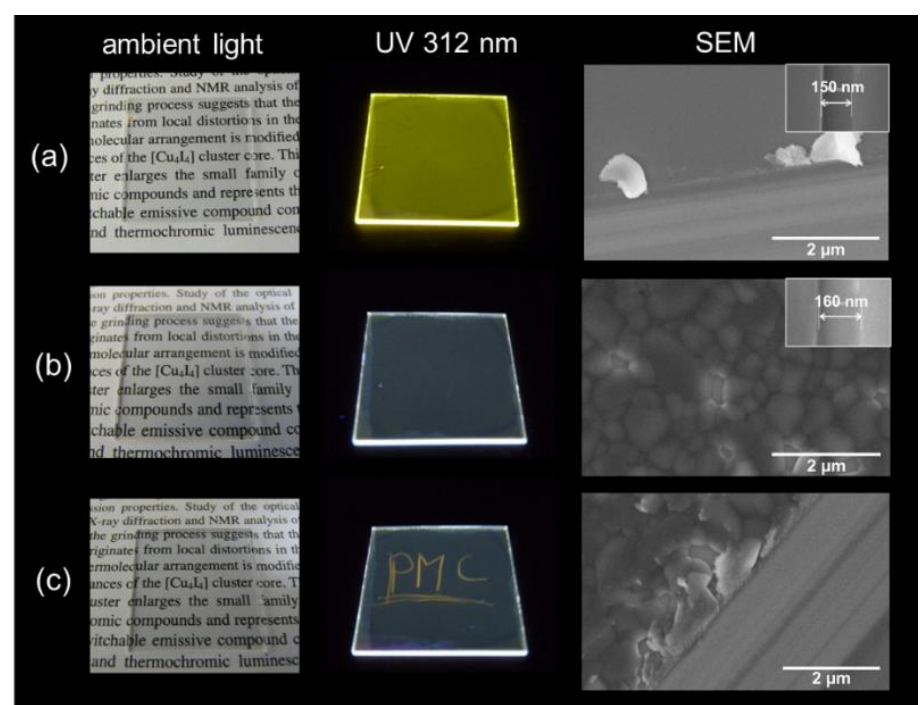

Figure 12. Photos of mechanically-responsive films of $\left[\mathrm{Cu}_{4} \mathrm{I}_{4}\left(\mathrm{PPh}_{2} \mathrm{CH}_{2} \mathrm{CH}=\mathrm{CH}_{2}\right)_{4}\right]$ deposited on glass substrate under ambient light and UV irradiation, (a) as-synthesized, (b) after annealing at $100{ }^{\circ} \mathrm{C}$ and (c) after writing 'PMC' with a stick on the surface and corresponding SEM images.

As shown in Figure 12c, it is possible to write on these films by activating an intense yellow emission. The erasing process is simply achieved by a heat treatment, while maintaining the transparency of the film. The luminescence mechanochromism behavior of these films is therefore similar to the cluster in powder. Initially, the film contains many defects of yellow luminescence which are suppressed by annealing. Writing creates such defects exactly where the mechanical stress is applied.

\section{Conclusions and Perspectives.}

This survey regarding the mechanochromic luminescent $\left[\mathrm{Cu}_{4} \mathrm{I}_{4} \mathrm{~L}_{4}\right]$ cubane copper iodide clusters, highlights their rich mechanically-responsive properties along with the specificities of the underlying mechanism. Mechanistic investigations conducted by employing different characterization techniques combined with theoretical studies, lead to the conclusion that the main actors in this phenomenon are the $\mathrm{Cu}(\mathrm{I})-\mathrm{Cu}(\mathrm{I})$ interactions. The mechanical solicitations induce changes in the intermolecular interactions which consequently modify the molecular structure of the cluster and in particular these intramolecular $\mathrm{Cu}-\mathrm{Cu}$ interactions. Because the latter are deeply implied in the triplet state responsible for the emission, their small modifications induce drastic emission changes. The mechanochromism thus results from a subtle competition between intermolecular and intramolecular interactions. The driving force is indeed the formation of a metastable state which is created by specific intermolecular interactions in the crystal packing. This metastable state is the $\left[\mathrm{Cu}_{4} \mathrm{I}_{4} \mathrm{~L}_{4}\right]$ molecular structure with relatively long intramolecular $\mathrm{Cu}-\mathrm{Cu}$ distances. Because the crystal packing of these molecular materials is relatively soft, it is sensitive to mechanical forces. As demonstrated by a possible prediction, long intramolecular $\mathrm{Cu}-\mathrm{Cu}$ distances is a prerequisite for mechanochromism to occur. However, it is a necessary but not a sufficient condition, the resulting molecular structure should be metastable to allow the $\mathrm{Cu}-\mathrm{Cu}$ to be shortened. This parameter is rather difficult to control. Nevertheless, the use of phosphine ligands appears to be a relatively efficient way since the majority of the mechanochromic clusters are coordinated by phosphines. The higher steric hindrance of these 
ligands compared with the nitrogen-based ones, can favor structural competition generating at the same time relatively long $\mathrm{Cu}-\mathrm{Cu}$ distances and crystalline constraints.

Considering mechanochromic compounds in general, a mechanism based on intramolecular changes is rarely encountered. Indeed, mechanisms result more commonly from changes of intermolecular interactions, as illustrated by the examples of excimers interplay and mononuclear coordination complexes. The particularity of the molecular cubane structure plays an important role. This compact structure built on $\mathrm{Cu}-\mathrm{P}$ coordination bonds, $\mathrm{Cu}-\mathrm{I}$ ionic bonds and on $\mathrm{Cu}-\mathrm{Cu}$ cuprophilic interactions, is highly flexible. Because of their weakest energy, associated to the supple coordination sphere of the $\mathrm{d}^{10} \mathrm{Cu}(\mathrm{I})$ centers, the $\mathrm{Cu}-\mathrm{Cu}$ interactions are the fitting parameters to adapt to their environment. This is actually clearly demonstrated by the crystalline polymorphism presented by this family of compounds. The influence of these metal-metal interactions to photophysical processes are at the origin of the remarkable multi-stimuli responsive properties of these clusters. In this framework, polynuclear copper complexes appear to be particularly relevant for designing stimuli-responsive materials with numerous applications in the field of detection. As previously shown, several mechanochromic copper iodide clusters with geometries different from the cubane one are starting to emerge, that opens new avenues for enlarging the features of the mechanochromic luminescent properties. Widening the emission wavelengths range, improving the reversibility and even enhancing the sensitivity of the mechanochromic responses will effectively benefit the development of materials with targeted and tunable mechanochromic properties.

Although the perspectives of applications of this family of mechanochromic luminescent clusters are promising, some issues still need to be overcome. The synthesis of mechanically responsive films has been demonstrated but the limited reversibility, due to the relatively weak mechanical strength of the active layer, needs to be improved. Embedding the mechanochromic compound within a porous substrate could allow gaining in repeatability. Quantification of the forces necessary to trigger the luminescence changes, that is required for sensing applications, needs additionally to be conducted. Studying nanoparticles of these clusters could be an efficient way to enhance the sensitivity of the mechanochromic response. The synthesis of particles of crystalline character which are relatively stable in solution has already been achieved, that would make possible the direct synthesis of thin films. Mechanochromic luminescent nanoparticles could even be used as local probes to track and analyze force-induced processes known to occur in various media.

\section{Acknowledgments.}

All collaborators which contributed to the work on mechanochromic luminescent copper iodide clusters are gratefully acknowledged with special thanks to the Ph.D. students; Q. Benito, H. Huitorel and R. Utrera-Melero. DGA, Ecole Polytechnique and the 'Région Pays de la Loire' are thanked funding.

\section{References.}

1 A. L. Balch, Angew. Chem. Int. Ed., 2009, 48, 2641-2644.

2 Y. Sagara and T. Kato, Nat. Chem., 2009, 1, 605-610. 
3 Q. Zhu, K. Vliet, N. Holten- Andersen and A. Miserez, Adv. Funct. Mater., 2019, 29, 1808191.

4 G. Huang, Q. Xia, W. Huang, J. Tian, Z. He, B. S. Li and B. Z. Tang, Angew. Chem. Int. Ed., 2019, 58, 17814-17819.

5 T. Mutai, T. Sasaki, S. Sakamoto, I. Yoshikawa, H. Houjou and S. Takamizawa, Nat. Commun., 2020, 11, 1824.

6 H. Yu, X. Song, N. Xie, J. Wang, C. Li and Y. Wang, Adv. Funct. Mater., 2021, 31, 2007511.

7 J. Ren, Y. Wang, Y. Tian, Z. Liu, X. Xiao, J. Yang, M. Fang and Z. Li, Angew. Chem. Int. Ed., 2021, 60, 12335-12340.

8 C. Wang, D. Wang, V. Kozhevnikov, X. Dai, G. Turnbull, X. Chen, J. Kong, B. Z. Tang, Y. Li and B. B. Xu, Nat. Commun., 2020, 11, 1448.

9 M. E. McFadden and M. J. Robb, J. Am. Chem. Soc., 2019, 141, 11388-11392.

10S. Kato, S. Furukawa, D. Aoki, R. Goseki, K. Oikawa, K. Tsuchiya, N. Shimada, A. Maruyama, K. Numata and H. Otsuka, Nat. Commun., 2021, 12, 126.

11Z. Qiu, W. Zhao, M. Cao, Y. Wang, J. W. Y. Lam, Z. Zhang, X. Chen and B. Z. Tang, Adv. Mater., 2018, 30, 1803924.

12Z. Yang, Z. Chi, Z. Mao, Y. Zhang, S. Liu, J. Zhao, M. P. Aldred and Z. Chi, Mater. Chem. Front., 2018, 2, 861-890.

13L. Huang, C. Qian and Z. Ma, Chem. Eur. J., 2020, 26, 11914-11930.

14Z. Chi, X. Zhang, B. Xu, X. Zhou, C. Ma, Y. Zhang, S. Liu and J. Xu, Chem. Soc. Rev., 2012, 41, 3878-3896.

15X. Zhang, Z. Chi, Y. Zhang, S. Liu and J. Xu, J. Mater. Chem. C, 2013, 1, 3376-3390.

16J. Schneider, Y.-A. Lee, J. Perez, W. W. Brennessel, C. Flaschenriem and R. Eisenberg, Inorg. Chem., 2008, 47, 957-968.

17 V. J. Catalano and S. J. Horner, Inorg. Chem., 2003, 42, 8430-8438.

18Z. Assefa, M. A. Omary, B. G. McBurnett, A. A. Mohamed, H. H. Patterson, R. J. Staples and J. P. Fackler, Inorg. Chem., 2002, 41, 6274-6280.

19 A. Laguna, T. Lasanta, J. M. López-de-Luzuriaga, M. Monge, P. Naumov and M. E. Olmos, J. Am. Chem. Soc., 2010, 132, 456-457.

20 M. Osawa, I. Kawata, S. Igawa, M. Hoshino, T. Fukunaga and D. Hashizume, Chem. Eur. J., 2010, 16, 12114-12126.

21 I. O. Koshevoy, C.-L. Lin, A. J. Karttunen, M. Haukka, C.-W. Shih, P.-T. Chou, S. P. Tunik and T. A. Pakkanen, Chem. Commun., 2011, 47, 5533-5535.

22 A. Deák, C. Jobbágy, G. Marsi, M. Molnár, Z. Szakács and P. Baranyai, Chem. Eur. J., 2015, 21, 11495-11508.

23Z. Chen, J. Liang, Y. Nie, X. Xu, G.-A. Yu, J. Yin and S. H. Liu, Dalton Trans., 2015, 44, 17473-17477.

24T. Seki, K. Kobayashi, T. Mashimo and H. Ito, Chem. Commun., 2018, 54, 11136-11139.

25 N. M.-W. Wu, M. Ng and V. W.-W. Yam, Angew. Chem. Int. Ed., 2019, 58, 3027-3031.

26D. T. Walters, X. B. Powers, M. M. Olmstead and A. L. Balch, Chem. Eur. J., 2019, 25, 3849-3857.

27 Y. Dong, J. Zhang, A. Li, J. Gong, B. He, S. Xu, J. Yin, S. H. Liu and B. Z. Tang, J. Mater. Chem. C, 2020, 8, 894-899.

28T. Seki, K. Ida, H. Sato, S. Aono, S. Sakaki and H. Ito, Chem. Eur. J., 2020, 26, 735-744. 29L. M. C. Luong, M. M. Olmstead and A. L. Balch, Chem. Commun., 2021, 57, 793-796.

30 V. N. Kozhevnikov, B. Donnio and D. W. Bruce, Angew. Chem. Int. Ed., 2008, 47, 62866289.

31 Y. Nishiuchi, A. Takayama, T. Suzuki and K. Shinozaki, Eur. J. Inorg. Chem., 2011, $1815-1823$. 
32 S. J. Choi, J. Kuwabara, Y. Nishimura, T. Arai and T. Kanbara, Chem. Lett., 2012, 41, 6567.

33 X. Zhang, J.-Y. Wang, J. Ni, L.-Y. Zhang and Z.-N. Chen, Inorg. Chem., 2012, 51, 55695579.

34L.-M. Huang, G.-M. Tu, Y. Chi, W.-Y. Hung, Y.-C. Song, M.-R. Tseng, P.-T. Chou, G.-H. Lee, K.-T. Wong, S.-H. Cheng and W.-S. Tsai, J. Mater. Chem. C, 2013, 1, 7582-7592.

35 A. Han, P. Du, Z. Sun, H. Wu, H. Jia, R. Zhang, Z. Liang, R. Cao and R. Eisenberg, Inorg. Chem., 2014, 53, 3338-3344.

36K. Ohno, S. Yamaguchi, A. Nagasawa and T. Fujihara, Dalton Trans., 2016, 45, 54925503.

37 A. Chowdhury, P. Howlader and P. S. Mukherjee, Chem. Eur. J., 2016, 22, 1424-1434.

38C. Cuerva, J. A. Campo, M. Cano and C. Lodeiro, Chem. Eur. J., 2019, 25, 12046-12051.

39X. Zhang, L.-Y. Zhang, J.-Y. Wang, F.-R. Dai and Z.-N. Chen, J. Mater. Chem. C, 2020, 8, $715-720$.

40L. Liu, X. Wang, N. Wang, T. Peng and S. Wang, Angew. Chem. Int. Ed., 2017, 56, 9160 9164.

41 A. E. Norton, M. K. Abdolmaleki, J. Liang, M. Sharma, R. Golsby, A. Zoller, J. A. Krause,

W. B. Connick and S. Chatterjee, Chem. Commun., 2020, 56, 10175-10178.

42 S. Mizukami, H. Houjou, K. Sugaya, E. Koyama, H. Tokuhisa, T. Sasaki and M. Kanesato, Chem. Mater., 2005, 17, 50-56.

43 H. Xu, F. Liu, Y. Cui, B. Chen and G. Qian, Chem. Commun., 2011, 47, 3153.

44B.-C. Tzeng, T.-Y. Chang, S.-L. Wei and H.-S. Sheu, Chem. Eur. J., 2012, 18, 5105-5112.

45X. Yan, X. Song, X. Mu and Y. Wang, New J. Chem., 2019, 43, 15886-15891.

46D. Qiao, J.-Y. Wang, L.-Y. Zhang, F.-R. Dai and Z.-N. Chen, Dalton Trans., 2019, 48, $11045-11051$.

47 S. Li, M. Wu, Y. Kang, H.-W. Zheng, X.-J. Zheng, D.-C. Fang and L.-P. Jin, Inorg. Chem., 2019, 58, 4626-4633.

48X. Song, H. Yu, X. Yan, Y. Zhang, Y. Miao, K. Ye and Y. Wang, Dalton Trans., 2018, 47, $6146-6155$.

49R. Zou, J. Zhang, S. Hu, F. Hu, H. Zhang and Z. Fu, CrystEngComm, 2017, 19, 62596262.

50H. Bi, D. Chen, D. Li, Y. Yuan, D. Xia, Z. Zhang, H. Zhang and Y. Wang, Chem. Commun., 2011, 47, 4135-4137.

51D. Yan, J. Lu, J. Ma, S. Qin, M. Wei, D. G. Evans and X. Duan, Angew. Chem. Int. Ed., 2011, 50, 7037-7040.

52T. F. Mastropietro, Y. J. Yadav, E. I. Szerb, A. M. Talarico, M. Ghedini and A. Crispini, Dalton Trans., 2012, 41, 8899.

53E. I. Szerb, A. M. Talarico, I. Aiello, A. Crispini, N. Godbert, D. Pucci, T. Pugliese and M. Ghedini, Eur. J. Inorg. Chem., 2010, 2010, 3270-3277.

54G.-G. Shan, H.-B. Li, H.-T. Cao, D.-X. Zhu, P. Li, Z.-M. Su and Y. Liao, Chem. Commun., 2012, 48, 2000.

55 G.-G. Shan, H.-B. Li, D.-X. Zhu, Z.-M. Su and Y. Liao, J. Mater. Chem., 2012, 22, 1273612744.

56 G. Li, T. Yang, K. Shao, Y. Gao, G. Shan, Z. Su, X. Wang and D. Zhu, Inorg. Chem., 2021, 60, 3741-3748.

57T. Yang, Y. Wang, X. Liu, G. Li, W. Che, D. Zhu, Z. Su and M. R. Bryce, Chem. Commun., 2019, 55, 14582-14585.

58 K. Rui, Z.-Y. Wang, Q.-Z. Yuan and D.-K. Cao, Dalton Trans., 2019, 48, 15114-15120.

59X. Zhu, P. Cui, S. Kilina and W. Sun, Inorg. Chem., 2017, 17. 
60 Y. Han, H.-T. Cao, H.-Z. Sun, Y. Wu, G.-G. Shan, Z.-M. Su, X.-G. Hou and Y. Liao, J. Mater. Chem. C, 2014, 2, 7648-7655.

61 G.-G. Shan, H.-B. Li, H.-Z. Sun, D.-X. Zhu, H.-T. Cao and Z.-M. Su, J. Mater. Chem. C, 2013, 1, 1440-1449.

62 Y. Pei, J. Xie, D. Cui, S. Liu, G. Li, D. Zhu and Z. Su, Dalton Trans., 2020, 49, 1306613071.

63 T. Tsukuda, M. Kawase, A. Dairiki, K. Matsumoto and T. Tsubomura, Chem. Commun., 2010, 46, 1905-1907.

64 M. G. Babashkina, D. A. Safin, M. Bolte and Y. Garcia, Dalton Trans., 2011, 40, $8523-$ 8526.

65Q.-Q. Sun, Q. Li, H.-Y. Li, M.-M. Zhang, M.-E. Sun, S. Li, Z. Quan and S.-Q. Zang, Chem. Commun., 2021, 57, 2372-2375.

66J.-S. Yang, M.-M. Zhang, Z. Han, H.-Y. Li, L.-K. Li, X.-Y. Dong, S.-Q. Zang and T. C. W. Mak, Chem. Commun., 2020, 56, 2451-2454.

67Y. Shi, Z. Lu, L. Zheng and Q.-E. Cao, Inorg. Chem., 2020, 59, 6508-6517.

68 K.-Y. Song, L.-M. Zhao, W.-T. Zhang, Y. Li, H.-H. Li and Z.-R. Chen, Cryst. Growth Des., 2019, 16.

69Z. Lu, Y. Cheng, W. Fan, S. Yang, X. Liu, Y. Qin, R. Zhao, L. Zheng and H. Zhang, Chem. Commun., 2019, 55, 8474-8477.

70 V. Conejo-Rodríguez, M. N. Peñas-Defrutos and P. Espinet, Dalton Trans., 2019, 48, 10412-10416.

71 X. Zhang, J.-Y. Wang, D. Qiao and Z.-N. Chen, J. Mater. Chem. C, 2017, 5, 8782-8787.

72 G. R. Krishna, M. S. R. N. Kiran, C. L. Fraser, U. Ramamurty and C. M. Reddy, $A d v$.

Funct. Mater., 2013, 23, 1422-1430.

73C.-X. Yan, Q.-Q. Lin, S. Li, C.-J. Wu, Y.-A. Li, J.-Z. Fan, J.-P. Ma, Y. Geng and Y.-B.

Dong, Chem. Commun., 2020, 56, 14435-14438.

74 Y. Qi, N. Ding, Z. Wang, L. Xu and Y. Fang, ACS Appl. Mater. Interfaces, 2019, 9.

75 N. D. Nguyen, G. Zhang, J. Lu, A. E. Sherman and C. L. Fraser, J. Mater. Chem., 2011, 7.

76T. Butler, F. Wang, M. L. Daly, C. A. DeRosa, D. A. Dickie, M. Sabat and C. L. Fraser, J. Phys. Chem. C, 2019, 123, 25788-25800.

77 T. Butler, W. A. Morris, J. Samonina-Kosicka and C. L. Fraser, ACS Appl. Mater. Interfaces, 2016, 10.

78P.-Z. Chen, H. Zhang, L.-Y. Niu, Y. Zhang, Y.-Z. Chen, H.-B. Fu and Q.-Z. Yang, $A d v$. Funct. Mater., 2017, 27, 1700332.

79M. Louis, C. Piñero García, A. Brosseau, C. Allain and R. Métivier, J. Phys. Chem. Lett., 2019, 10, 4758-4762.

80Z. Zhang, P. Xue, P. Gong, G. Zhang, J. Peng and R. Lu, J. Mater. Chem. C, 2014, 2, 9543-9551.

81 G. Zhang, J. Lu, M. Sabat and C. L. Fraser, J. Am. Chem. Soc., 2010, 132, 2160-2162.

82R. Yoshii, K. Suenaga, K. Tanaka and Y. Chujo, Chem. Eur. J., 2015, 21, 7231-7237.

83T. Wen, D.-X. Zhang, J. Liu, R. Lin and J. Zhang, Chem. Commun., 2013, 49, 5660-5662.

84T. Wen, D.-X. Zhang, H.-X. Zhang, H.-B. Zhang, J. Zhang and D.-S. Li, Chem. Commun., 2014, 50, 8754-8756.

85T. Wen, X.-P. Zhou, D.-X. Zhang and D. Li, Chem. Eur. J., 2014, 20, 644-648.

86Q. Xiao, J. Zheng, M. Li, S.-Z. Zhan, J.-H. Wang and D. Li, Inorg. Chem., 2014, 53, 11604-11615.

87T. Wen, D.-X. Zhang, J. Liu, H.-X. Zhang and J. Zhang, Chem. Commun., 2015, 3.

88 K. Chen, M. M. Nenzel, T. M. Brown and V. J. Catalano, Inorg. Chem., 2015, 54, 69006909.

89E. Kwon, J. Kim, K. Y. Lee and T. H. Kim, Inorg. Chem., 2017, 56, 943-949. 
90L.-X. Hu, M. Gao, T. Wen, Y. Kang and S. Chen, Inorg. Chem., 2017, 56, 6507-6511.

91 D.-X. Zhang, H.-X. Zhang, T. Wen, D.-S. Li and J. Zhang, Inorg. Chem. Front., 2016, 3, 263-267.

92 J. Conesa-Egea, J. Gallardo-Martínez, S. Delgado, J. I. Martínez, J. Gonzalez-Platas, V.

Fernández-Moreira, U. R. Rodríguez-Mendoza, P. Ocón, F. Zamora and P. Amo-Ochoa, Small, 2017, 13, 1700965.

93 T. Lu, J.-Y. Wang, D. Tu, Z.-N. Chen, X.-T. Chen and Z.-L. Xue, Inorg. Chem., 2018, 57, 13618-13630.

94 N. Feng, C. Gao, C.-Y. Guo and G. Chen, ACS Appl. Mater. Interfaces, 2018, 10, 5603-5608.

95 B. Hupp, J. Nitsch, T. Schmitt, R. Bertermann, K. Edkins, F. Hirsch, I. Fischer, M. Auth, A. Sperlich and A. Steffen, Angew. Chem. Int. Ed., 2018, 57, 13671-13675.

96 A. Liske, L. Wallbaum, T. Ho, C. Ganter, C. M. Marian and A. Ste, Inorg. Chem., 2019, 58, 5433-5445.

97 A. Vacher, A. Amar, F. Camerel, Y. Molard, C. Latouche, T. Roisnel, V. Dorcet, A.

Boucekkine, H. Akdas-Kiliç and M. Achard, Dalton Trans., 2019, 48, 2128-2134.

98 M. Yang, X.-L. Chen and C.-Z. Lu, Dalton Trans., 2019, 48, 10790-10794.

99L. Hu, A. Zheng, Y. Kang, T. Wen and J. Zhang, Chem. Commun., 2020, 56, 3967-3970.

100 Y. Thefioux, M. Cordier, F. Massuyeau, C. Latouche, C. Martineau-Corcos and S.

Perruchas, Inorg. Chem., 2020, 59, 5768-5780.

101 C. Li, W. Li, A. F. Henwood, D. Hall, D. B. Cordes, A. M. Z. Slawin, V. Lemaur, Y.

Olivier, I. D. W. Samuel and E. Zysman-Colman, Inorg. Chem., 2020, 59, 14772-14784.

102 D. Peng, L.-H. He, P. Ju, J.-L. Chen, H.-Y. Ye, J.-Y. Wang, S.-J. Liu and H.-R. Wen, Inorg. Chem., 2020, 59, 17213-17223.

103 R. Kobayashi, H. Imoto and K. Naka, Eur. J. Inorg. Chem., 2020, 3548-3553.

104 X.-W. Chen, L.-H. He, P. Ju, J.-L. Chen, S.-J. Liu and H.-R. Wen, J. Mater. Chem. C, 2020, 8, 16160-16167.

105 X. Yu, X. Li, Z. Cai, L. Sun, C. Wang, H. Rao, C. Wei, Z. Bian, Q. Jin and Z. Liu, Chem. Commun., 2021, 57, 5082-5085.

106 O. S. Wenger, J. Am. Chem. Soc., 2018, 140, 13522-13533.

107 S. Perruchas, X. F. Le Goff, S. Maron, I. Maurin, F. Guillen, A. Garcia, T. Gacoin and J.-P. Boilot, J. Am. Chem. Soc., 2010, 132, 10967-10969.

108 M. R. Churchill and K. L. Kalra, Inorg. Chem., 1974, 13, 1065-1071.

109 X.-C. Shan, F.-L. Jiang, H. Zhang, X.-Y. Qian, L. Chen, M.-Y. Wu, S. A. AL-Thabaiti and M.-C. Hong, Chem. Commun., 2013, 49, 10227-10229.

110 X.-C. Shan, F.-L. Jiang, L. Chen, M.-Y. Wu, J. Pan, X.-Y. Wan and M.-C. Hong, J. Mater. Chem. C, 2013, 1, 4339-4349.

111 X.-C. Shan, H.-B. Zhang, L. Chen, M.-Y. Wu, F.-L. Jiang and M.-C. Hong, Cryst. Growth Des., 2013, 13, 377-1381.

112 Q. Benito, X. F. Le Goff, S. Maron, A. Fargues, A. Garcia, C. Martineau, F. Taulelle, S. Kahlal, T. Gacoin, J.-P. Boilot and S. Perruchas, J. Am. Chem. Soc., 2014, 136, 1131111320.

113 Q. Benito, I. Maurin, T. Cheisson, G. Nocton, A. Fargues, A. Garcia, C. Martineau, T. Gacoin, J.-P. Boilot and S. Perruchas, Chem. Eur. J., 2015, 21, 5892-5897.

114 M. S. Deshmukh, A. Yadav, R. Pant and R. Boomishankar, Inorg. Chem., 2015, 54, $1337-1345$.

115 K. Yang, S.-L. Li, F.-Q. Zhang and X.-M. Zhang, Inorg. Chem., 2016, 55, 7323-7325.

116 Q. Benito, I. Maurin, M. Poggi, C. Martineau-Corcos, T. Gacoin, J.-P. Boilot and S.

Perruchas, J. Mater. Chem. C, 2016, 4, 11231-11237. 
117 B. Huitorel, Q. Benito, A. Fargues, A. Garcia, T. Gacoin, J.-P. Boilot, S. Perruchas and F. Camerel, Chem. Mater., 2016, 28, 8190-8200.

118 B. Huitorel, H. El Moll, M. Cordier, A. Fargues, A. Garcia, F. Massuyeau, C.

Martineau-Corcos, T. Gacoin and S. Perruchas, Inorg. Chem., 2017, 56, 12379-12388.

119 A. Kobayashi, Y. Yoshida, M. Yoshida and M. Kato, Chem. Eur. J., 2018, 24, 1475014759.

120 A. Neshat, R. B. Aghakhanpour, P. Mastrorilli, S. Todisco, F. Molani and A.

Wojtczak, Polyhedron, 2018, 154, 217-228.

121 S.-Y. Yin, Z. Wang, Z.-M. Liu, H.-J. Yu, J.-H. Zhang, Y. Wang, R. Mao, M. Pan and

C.-Y. Su, Inorg. Chem., 2019, 58, 10736-10742.

122 B. Huitorel, R. Utrera-Melero, F. Massuyeau, J.-Y. Mevelec, B. Baptiste, A. Polian, T. Gacoin, C. Martineau-Corcos and S. Perruchas, Dalton Trans., 2019, 48, 7899-7909.

123 R. Utrera-Melero, B. Huitorel, M. Cordier, J.-Y. Mevellec, F. Massuyeau, C.

Latouche, C. Martineau-Corcos and S. Perruchas, Inorg. Chem., 2020, 59, 13607-13620.

124 T.-L. Yu, Y.-M. Guo, G.-X. Wu, X.-F. Yang, M. Xue, Y.-L. Fu and M.-S. Wang,

Coord. Chem. Rev., 2019, 397, 91-111.

125 E. Cariati, E. Lucenti, C. Botta, U. Giovanella, D. Marinotto and S. Righetto, Coord.

Chem. Rev., 2016, 306, 566-614.

126 A. Kobayashi and M. Kato, Chem. Lett., 2017, 46, 154-162.

127 R. Peng, M. Li and D. Li, Coord. Chem. Rev., 2010, 254, 1-18.

128 T. Jiang, Y. Zhu, J. Zhang, J. Zhu, M. Zhang and J. Qiu, Adv. Funct. Mater., 2019, 29, 1906068.

129 J. Troyano, F. Zamora and S. Delgado, Chem. Soc. Rev., 2021, 50, 4606-4628.

130 Y. Fang, W. Liu, S. J. Teat, G. Dey, Z. Shen, L. An, D. Yu, L. Wang, D. M. O’Carroll and J. Li, Adv. Funct. Mater., 2017, 27, 1603444.

131 C. Chen, R.-H. Li, B.-S. Zhu, K.-H. Wang, J.-S. Yao, Y.-C. Yin, M.-M. Yao, H.-B.

Yao and S.-H. Yu, Angew. Chem. Int. Ed., 2018, 57, 7106-7110.

132 M. Xie, C. Han, Q. Liang, J. Zhang, G. Xie and H. Xu, Sci. Adv., 2019, 5, eaav9857.

133 M. R. Churchill and K. L. Kalra, Inorg. Chem., 1974, 13, 1899-1904.

134 M. R. Churchill, B. G. DeBoer and S. J. Mendak, Inorg. Chem., 1975, 14, 2041-2047.

135 C. L. Raston and A. H. White, J. Chem. Soc., Dalton Trans., 1976, 2153-2156.

136 H. D. Hardt and A. Pierre, Z. Anorg. Allg. Chem., 1973, 402, 107-112.

137 M. Radjaipour and D. Oelkrug, Ber. Bunsen-Ges. Phys. Chem., 1978, 82, 159-163.

138 Arnd. Vogler and Horst. Kunkely, J. Am. Chem. Soc., 1986, 108, 7211-7212.

139 P. C. Ford, E. Cariati and J. Bourassa, Chem. Rev., 1999, 99, 3625-3648.

140 K. R. Kyle and P. C. Ford, J. Am. Chem. Soc., 1989, 111, 5005-5006.

141 D. C. Lai and J. I. Zink, Inorg. Chem., 1993, 32, 2594-2596.

142 S. Perruchas, C. Tard, X. F. Le Goff, A. Fargues, A. Garcia, S. Kahlal, J.-Y. Saillard,

T. Gacoin and J.-P. Boilot, Inorg. Chem., 2011, 50, 10682-10692.

143 T. H. Kim, Y. W. Shin, J. H. Jung, J. S. Kim and J. Kim, Angew. Chem. Int. Ed., 2008, 47, 685-688.

144 M. Vitale, C. Kul, W. E. Palke and P. C. Ford', Inorg. Chem., 1994, 33, 561-566.

145 F. De Angelis, S. Fantacci, A. Sgamellotti, E. Cariati, R. Ugo and P. C. Ford, Inorg.

Chem., 2006, 45, 10576-10584.

146 CSD Cambridge data base, 2021.

147 A. Bondi, J. Phys. Chem., 1964, 68, 441-451.

148 S. Sculfort and P. Braunstein, Chem. Soc. Rev., 2011, 40, 2741-2760.

149 B. Huitorel, H. El Moll, R. Utrera-Melero, M. Cordier, A. Fargues, A. Garcia, F.

Massuyeau, C. Martineau-Corcos, F. Fayon, A. Rakhmatullin, S. Kahlal, J.-Y. Saillard, T.

Gacoin and S. Perruchas, Inorg. Chem., 2018, 57, 4328-4339. 
150 Q. Benito, B. Baptiste, A. Polian, L. Delbes, L. Martinelli, T. Gacoin, J.-P. Boilot and S. Perruchas, Inorg. Chem., 2015, 54, 9821-9825.

151 A. Li, S. Xu, C. Bi, Y. Geng, H. Cui and W. Xu, Mater. Chem. Front., 2021, 5, 25882606.

152 K. Nagura, S. Saito, H. Yusa, H. Yamawaki, H. Fujihisa, H. Sato, Y. Shimoikeda and S. Yamaguchi, J. Am. Chem. Soc., 2013, 135, 10322-10325.

153 C. H. Woodall, C. M. Beavers, J. Christensen, L. E. Hatcher, M. Intissar, A. Parlett, S. J. Teat, C. Reber and P. R. Raithby, Angew. Chem. Int. Ed., 2013, 52, 9691-9694.

154 Z. Wu, J. Liu, Y. Gao, H. Liu, T. Li, H. Zou, Z. Wang, K. Zhang, Y. Wang, H. Zhang and B. Yang, J. Am. Chem. Soc., 2015, 137, 12906-12913.

155 H. Kitagawa, Y. Ozawa and K. Toriumi, Chem. Commun., 2010, 46, 6302-6304.

156 L. Maini, D. Braga, P. P. Mazzeo and B. Ventura, Dalton Trans., 2012, 41, 531-539.

157 Y. Hong, J. W. Y. Lam and B. Z. Tang, Chem. Soc. Rev., 2011, 40, 5361-5388.

158 S.-J. Yoon, J. W. Chung, J. Gierschner, K. S. Kim, M.-G. Choi, D. Kim and S. Y. Park, J. Am. Chem. Soc., 2010, 132, 13675-13683.

159 Y. Q. Dong, J. W. Y. Lam and B. Z. Tang, J. Phys. Chem. Lett., 2015, 6, 3429-3436.

160 B. Xu, Z. Chi, J. Zhang, X. Zhang, H. Li, X. Li, S. Liu, Y. Zhang and J. Xu, Chem. Asian J., 2011, 6, 1470-1478.

161 R. Utrera- Melero, J. Mevellec, N. Gautier, N. Stephant, F. Massuyeau and S. Perruchas, Chem. Asian J., 2019, 14, 3166-3172.

162 H. Ito, M. Muromoto, S. Kurenuma, S. Ishizaka, N. Kitamura, H. Sato and T. Seki, Nat. Commun., 2013, 4, 2009-2014. 